\title{
Human Endothelial Colony-Forming Cells Protect against Acute Kidney Injury
}

\section{Role of Exosomes}

\author{
Dylan Burger, * Jose L. Viñas, * Shareef Akbari, * Hajira Dehak, * William Knoll, * Alex Gutsol, * Anthony Carter, * \\ Rhian M. Touyz, ${ }^{* \dagger}$ David S. Allan, ${ }^{\ddagger}$ and Kevin D. Burns*
}

\begin{abstract}
From the Kidney Research Centre, * Division of Nephrology, and the Division of Hematology, ${ }^{\ddagger}$ Department of Medicine, Ottawa Hospital Research Institute, University of Ottawa, Ottawa, Ontario, Canada; and the Institute of Cardiovascular and Medical Sciences, ${ }^{\dagger}$ British Heart Foundation Glasgow

Cardiovascular Research Centre, University of Glasgow, Glasgow, United Kingdom
\end{abstract}

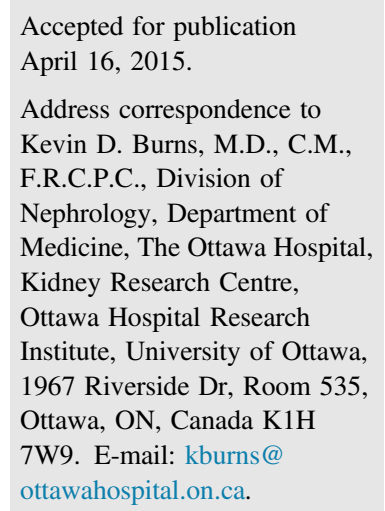

\begin{abstract}
The administration of certain progenitor cells is protective in experimental acute kidney injury (AKI), and mechanisms may involve the release of paracrine factors. Endothelial colony-forming cells (ECFCs) are endothelial precursor cells with a high proliferative capacity and pro-angiogenic potential. We examined the effects of human umbilical cord blood-derived ECFCs and their extracellular vesicles in a mouse model of ischemic AKI and in cultured human umbilical vein endothelial cells subjected to hypoxia/reoxygenation. In mice with ischemic AKI, administration of ECFCs (i.v.) at the time of reperfusion significantly attenuated increases in plasma creatinine, tubular necrosis, macrophage infiltration, oxidative stress, and apoptosis, without cell persistence in the kidneys. In cultured human umbilical vein endothelial cells, hypoxia/ reoxygenation stimulated apoptosis. This effect was inhibited by incubation with conditioned medium or exosomes (40- to 100-nm diameter) derived from ECFCs, but not by microparticles (100- to 1000-nm diameter) or vesicle-depleted conditioned medium. Administration of exosomes (i.v.) directly to mice with ischemic AKI attenuated renal injury, as assessed by plasma creatinine, tubular necrosis, and apoptosis. Taken together, these studies indicate protective effects of human cord blood-derived ECFCs in experimental AKI and suggest that ECFC-derived exosomes may mediate the protective response via inhibition of endothelial cell apoptosis. (Am J Pathol 2015, 185: 2309-2323; http://dx.doi.org/10.1016/j.ajpath.2015.04.010)
\end{abstract}

Acute kidney injury (AKI) carries a high mortality rate and has limited therapeutic options. ${ }^{1}$ The principal cause of AKI is ischemia/reperfusion (I/R) injury, with hypoperfusion rapidly reducing glomerular filtration and ultimately causing acute tubular necrosis. ${ }^{2}$ Renal vascular injury accompanies tubular damage with reductions in peritubular capillary blood flow, resulting in endothelial cell loss/apoptosis, disrupted barrier function, and a shift to a procoagulant, proinflammatory phenotype. $^{3,4}$

Studies in animal models of AKI indicate that the administration of certain stem/progenitor cells accelerates renal recovery. ${ }^{5-7}$ Conversely, we have shown that human umbilical cord blood-derived $\mathrm{CD}_{133^{+}}$progenitors, which have pro-angiogenic properties, ${ }^{8}$ exacerbate ischemic AKI in mice, associated with increased circulating levels of human tumor necrosis factor- $\alpha .{ }^{9}$ Therefore, there is a need for careful selection and characterization of the population used in any cell-based approach to treatment of human AKI. In this regard, the administration of exogenous cells of endothelial lineage

Supported by Kidney Foundation of Canada grant BRG-KFOC140011 (K.D.B.) and the Department of Medicine, University of Ottawa (K.D.B.). D.B. was supported by a fellowship from the Kidney Research Scientist Core Education and National Training program and a Heart and Stroke Foundation/Pfizer Canada Research Fellowship.

D.B. and J.L.V. contributed equally to this work.

Disclosures: None declared.

Portions of this work were presented in abstract form at the American Society of Nephrology Kidney Week 2013, held November 5-10, 2013, in Atlanta, GA. 


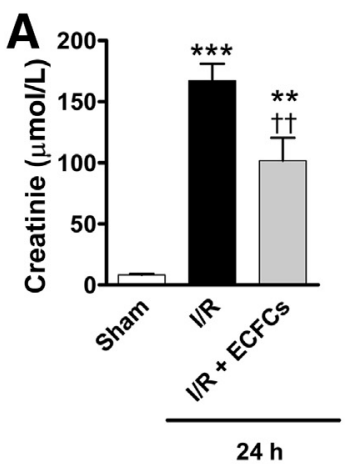

C

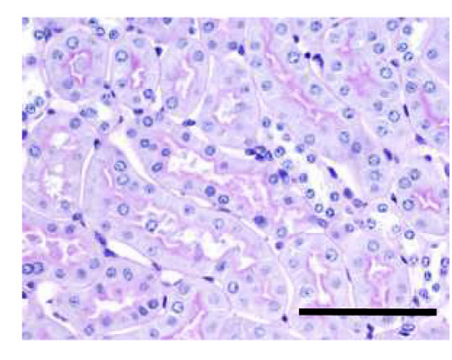

D

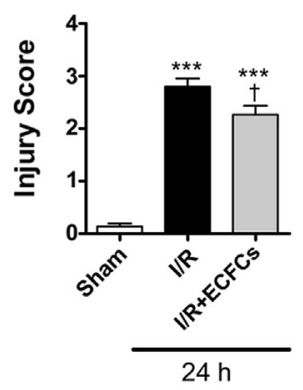

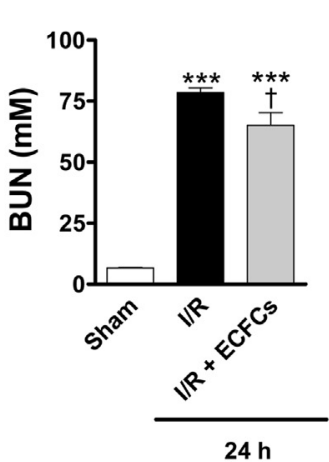

$24 \mathrm{~h}$

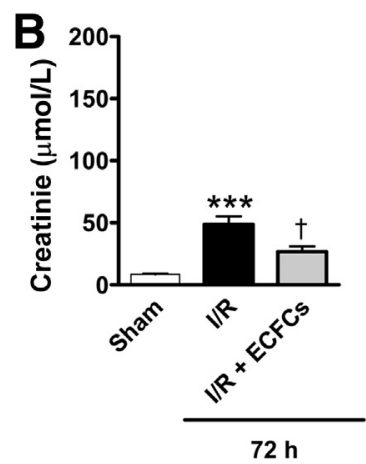

$72 \mathrm{~h}$

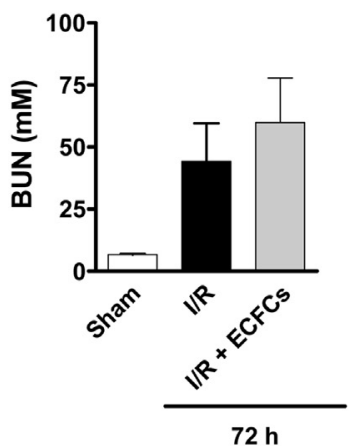

I/R + ECFCs (24 h)
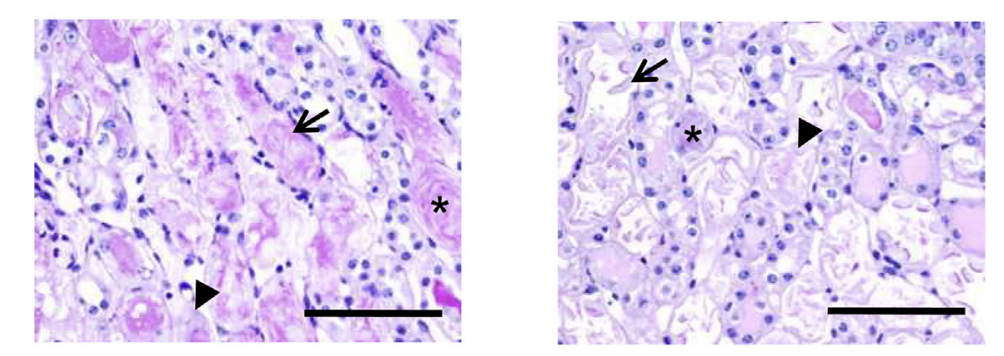

Figure 1 Effect of endothelial colony-forming cells (ECFCs) on kidney ischemia/reperfusion (I/R) injury in mice. Mice were subjected to sham surgery or 30 minutes of kidney ischemia, followed by 24 or 72 hours of reperfusion, and treated with ECFCs $\left(10^{6}\right.$ per mouse, i.v. $)$ or vehicle at the time of reperfusion. Shown are plasma creatinine and blood urea nitrogen (BUN) at 24 (A) and 72 (B) hours after reperfusion. C-E: Representative images (C) and scoring (D and $\mathbf{E}$ ) of corticomedullary tubular injury. I/R injury was associated with hallmark tubular dilatation (arrows), cast formation (asterisk), and nuclear loss (arrowheads). This was partially attenuated after ECFC administration. Objective: Plan-Apochromat 20x (numerical aperture, 0.80; Carl Zeiss AG, Oberkochen, Germany). ${ }^{* *} P<0.01,{ }^{* * *} P<0.001$ versus sham; ${ }^{\dagger} P<0.05,{ }^{\dagger \dagger} P<0.01$ versus respective I/R controls. Scale bar $=100 \mu \mathrm{m}(\mathrm{C})$.

has emerged as a strategy to accelerate endothelial and renal recovery in ischemic AKI. Brodsky et $\mathrm{al}^{10}$ first highlighted this approach showing that infusion of human umbilical vein endothelial cells (HUVECs) protects rodent kidneys from ischemic injury.

Endothelial colony-forming cells (ECFCs) are early lineage endothelial progenitors that are readily isolated from both human cord and peripheral blood samples. ${ }^{11}$ In contrast to other endothelial progenitor populations, ECFCs exclusively express markers of endothelial lineage and are free of hematopoietic contamination. ${ }^{11}$ ECFCs have considerable therapeutic potential because of their high proliferative capacity, and are more potent than terminally differentiated endothelial cells (eg, HUVECs) in promoting postischemic revascularization. ${ }^{12}$ The beneficial effects do not appear to require cell engraftment, suggesting that factors released from the cells stimulate repair in a paracrine manner. ${ }^{13}$ Consistent with this infusion of extracellular vesicles (EVs) derived from endothelial precursor cells accelerates renal recovery in rodent models of AKI. ${ }^{14-17}$ However, whether human cord blood-derived ECFCs are directly protective in ischemic
AKI is not known. Furthermore, as cells release distinct classes of EVs, the roles of ECFC-derived exosomes (40to 100-nm diameter) and microparticles (MPs; 100- to 1000-nm diameter) have not been studied. Herein, we show that ECFCs and their exosomes mediate protective effects in a mouse model of ischemic AKI, and demonstrate a role for ECFC-derived exosomes in attenuating hypoxia-induced endothelial cell apoptosis in vitro.

\section{Materials and Methods}

\section{Animals}

Male nonobese diabetic-severe combined immunodeficient

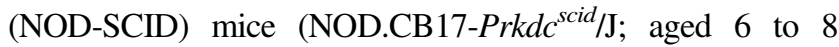
weeks) were used to avoid any immune response to human ECFCs, as described. ${ }^{9}$ Mice were housed at the University of Ottawa (Ottawa, ON, Canada) Animal Care facilities with access to food and water ad libitum. Protocols were approved by the Animal Ethics Committee at the University of Ottawa and performed according to the recommendations of the Canadian Council for Animal Care. 

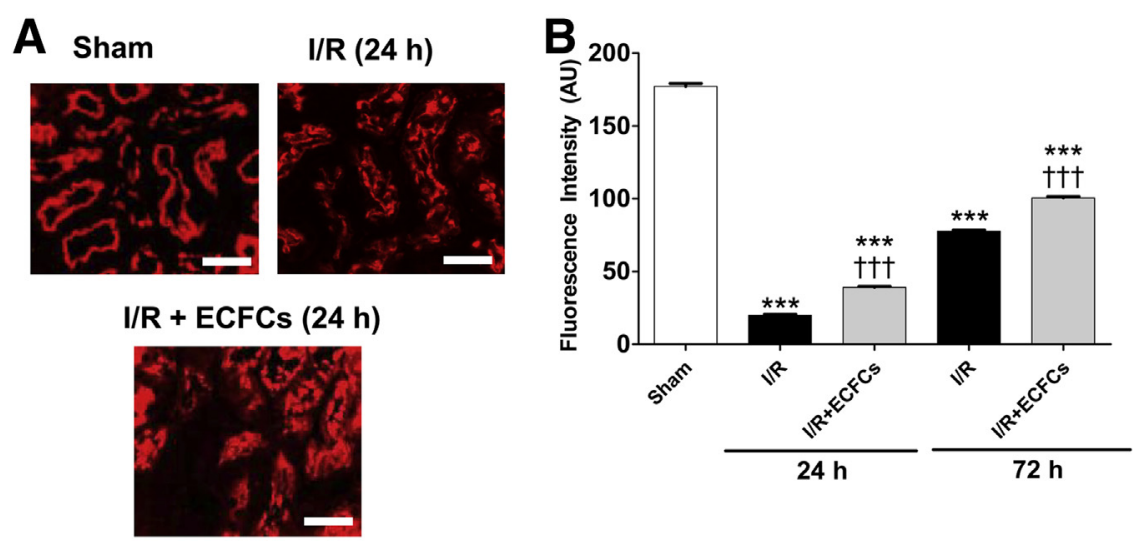

Figure 2 Effect of endothelial colony-forming cells (ECFCs) on kidney ischemia/reperfusion (I/R) histological injury in mice. Representative images (A) and semiquantitative analysis (B) of corticomedullary proximal tubule megalin expression (red fluorescence). Objective: Zeiss Plan-NeoFluar 40x (numerical aperture, 1.3-oil; Carl Zeiss AG). Representative images $(\mathbf{C})$ and semiquantitative analysis (D) of corticomedullary $\alpha$-smooth muscle actin (SMA; green fluorescence). Images are 72 hours after reperfusion. Objective: Zeiss Plan-NeoFluar 40x (numerical aperture, 1.3-oil; Carl Zeiss AG). Data are presented as means \pm SEM (B and D). $n=5$ to 6 (B and D). ${ }^{* *} P<0.001$ versus sham; ${ }^{\dagger \dagger \dagger} P<0.001$ versus respective I/R controls; ${ }^{\ddagger \ddagger \ddagger} P<0.001$ versus I/ $\mathrm{R}$ (72 hours). Scale bar $=100 \mu \mathrm{m}(\mathbf{A}$ and $\mathbf{C})$. AU, arbitrary unit.
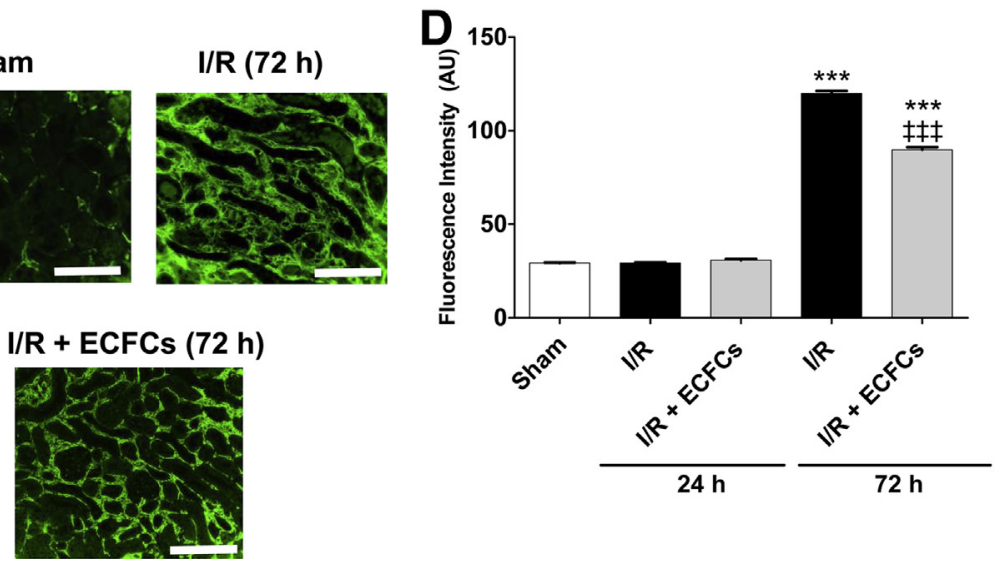

\section{Isolation and Culture of ECFCs}

ECFCs were isolated from human umbilical cord blood units obtained at The Ottawa Hospital (Ottawa, ON, Canada) after informed written consent and with approval from the institutional research ethics board, as described. ${ }^{18}$ After isolation, ECFCs were cultured in endothelial basal medium 2 supplemented with SingleQuot supplements (Lonza, Basel, Switzerland), $10 \%$ (v/v) fetal bovine serum, and $1 \%(\mathrm{v} / \mathrm{v})$ $10,000 \mathrm{U} / \mathrm{mL}$ penicillin/10,000 $\mu \mathrm{g} / \mathrm{mL}$ streptomycin $/ 25 \mu \mathrm{g} /$ $\mathrm{mL}$ amphotericin, as described. ${ }^{18}$ Cells were seeded onto tissue culture plates precoated with gelatin at $37^{\circ} \mathrm{C}, 5 \% \mathrm{CO}_{2}$, in a humidified incubator. Before injection, cells (passage 3 to 4 ) were detached using trypsin-EDTA, washed twice in $1 \times$ phosphate-buffered saline (PBS), and resuspended in $1 \times$ PBS at a final concentration of $10^{7}$ cells $/ \mathrm{mL}$.

\section{ECFC Characterization}

ECFCs were assessed for surface antigens by flow cytometry. Cell suspensions $\left(1 \times 10^{6}\right.$ cells in PBS) were incubated in the dark with human anti-CD31-fluorescein isothiocyanate (1:100; BD Pharmingen, San Jose, CA), anti-CD133-phosphatidylethanolamine (1:100; Miltenyi Biotech, Auburn, CA), anti-CD45-Pacific Blue (1:100; Miltenyi Biotech), anti-CD14-fluorescein isothiocyanate (1:100; Miltenyi Biotech), and anti-kinase insert domain receptor-peridinin chlorophyll (1:200; R\&D Systems, Minneapolis, MN) for 30 minutes. Samples were run on a MPL FC 500 cytometer (Beckman Coulter, Pasadena, CA), and data were analyzed using Cyflogic version 1.2.1.

\section{Kidney I/R Injury}

Bilateral kidney $\mathrm{I} / \mathrm{R}$ was performed on isofluraneanesthetized mice, as described, with modification. ${ }^{9}$ Mice were administered heparin (50 U i.p.) immediately before surgery and placed on a homeothermic blanket system (Harvard Apparatus, Holliston, MA) within a biological safety cabinet. Body temperature was monitored using a flexible rectal probe and maintained at $37^{\circ} \mathrm{C}$ throughout the experiment. Kidneys were exposed and surgical clamps were placed on the renal artery and vein of each kidney for 30 minutes. Before reperfusion, the right jugular vein was cannulated and mice received either vehicle (PBS, $100 \mu \mathrm{L})$ or ECFCs $\left(10^{6}\right.$ in $100 \mu \mathrm{L}$ PBS $)$ immediately after restoration of blood flow. Mice were sacrificed 24 and 72 hours after reperfusion. For ECFC treatment, the following experimental groups of mice were included: sham $(n=5)$, 24-hour $\mathrm{I} / \mathrm{R}(n=6)$, 24-hour $\mathrm{I} / \mathrm{R}+\operatorname{ECFCs}(n=6)$, 72-hour I/R $(n=6)$, and 72-hour I/R + ECFCs $(n=6)$. For exosome treatment, the following treatments were included: sham $(n=6), 24$-hour I/R $(n=6)$, and 24-hour $\mathrm{I} / \mathrm{R}+$ exosomes $(n=7)$. 


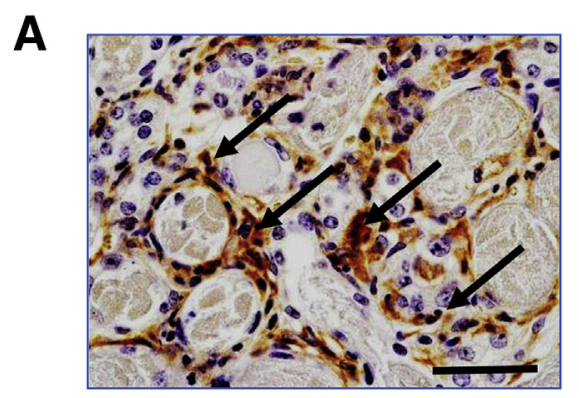

I/R (72 h)

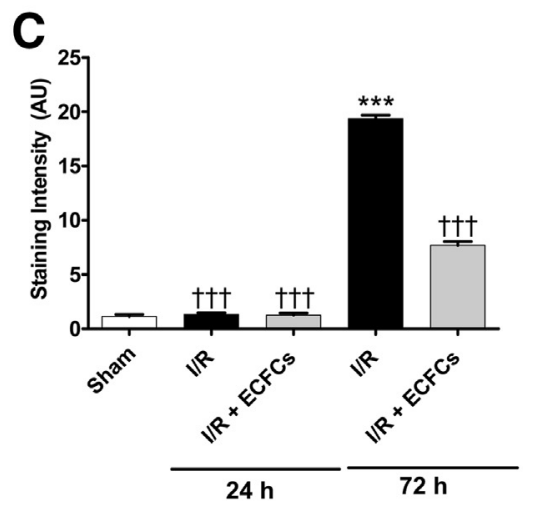

\section{Cell Tracking and Tissue Distribution}

Cell tracking experiments were performed as described. ${ }^{9}$ ECFCs were labeled with $10 \mu \mathrm{mol} / \mathrm{L}$ 5-chloromethylfluorescein diacetate (CFMDA; Molecular Probes, Burlington, ON, Canada) and quantified from frozen sections $(\times 40$ magnification) or in blood samples by flow cytometry immediately after infusion, and at 1 and 24 hours after infusion. Frozen sections were chosen to avoid strong autofluorescence seen in paraffin-embedded or formalinfixed sections of ischemic kidney. Tissues were collected in OCT medium (VWR, Radnor, PA) at $-80^{\circ} \mathrm{C}$, and cryosections ( $20 \mu \mathrm{m}$ thick) were adhered to glass slides, immediately immersed in PBS, rinsed for 10 to 30 minutes in PBS, and mounted with antifade adhesive Vectashield (Vector Laboratories, Burlingame, CA). For blood samples, the concentration of circulating CFMDA-positive ECFCs was determined by flow cytometry and expressed as a percentage of total ECFCs initially infused. For tissue samples, CFMDApositive cells were classified as high density $(>10$ cells per field of view), low density (1 to 9 cells per field of view), rare $(<1$ cell per field of view), or not detected. False-positive fluorescent labeling was distinguished from true ECFCs using the fluorescence colocalization technique. ${ }^{19}$

\section{Plasma Biochemistry}

Plasma creatinine levels were analyzed by cation-exchange high-performance liquid chromatography (HPLC) ${ }^{20}$ Plasma samples $(25 \mu \mathrm{L})$ were mixed with $100 \mu \mathrm{L}$ of acidified acetonitrile $(1: 200 \mathrm{v} / \mathrm{v}$ of glacial acetic acid and acetonitrile) to precipitate protein, and protein-free supernatants were vacuum dried. Dried pellets were resuspended in $25 \mu \mathrm{L}$ of mobile phase (15 mmol/L sodium acetate, $\mathrm{pH} 4.2$, with $4 \%$ methanol and $1 \%$ acetonitrile, with the $\mathrm{pH}$ adjusted using acetic acid). For HPLC analysis, $20 \mu \mathrm{L}$ of sample was injected and separated under isocratic conditions, with a flow rate of $0.3 \mathrm{~mL} / \mathrm{minute}$, a column temperature of $45^{\circ} \mathrm{C}$, and a run time of 15 minutes. An Agilent Zorbax 300 cation-exchange column (Agilent Technologies, Santa Clara, CA) with a 5- $\mu \mathrm{m}$ internal diameter was used, and creatinine was monitored by absorption at $225 \mathrm{~nm}$ with an approximate retention time of 6.0 minutes.

Blood urea nitrogen (BUN) was analyzed from plasma samples by IDEXX Laboratories (Markham, ON, Canada).

\section{Histology}

At sacrifice, mouse kidneys were fixed in $4 \%$ formalin, dehydrated, and embedded in paraffin. Tissues were cut into sections $(5 \mu \mathrm{m}$ thick) and stained with hematoxylin and eosin, and periodic acid-Schiff. All histological analyses were performed in a blinded manner by a renal pathologist (A.G.). The extent of tubular injury was semiquantified using a scoring system ranging from 0 to $4 .^{21,22}$ Scoring was performed by randomly scanning each section for the outer stripe of the outer medulla (at least 40 fields at $\times 200$ magnification). Signs of tubular injury were identified as tubular dilatation, loss of brush border, nuclear loss, sloughing of tubular cells, or cast formation. The scoring system was as follows: 0 indicates no tubular injury; $1,<25 \%$ of tubules injured; $2,26 \%$ to $50 \%$ of tubules injured; $3,51 \%$ to $75 \%$ of tubules injured; and $4,>75 \%$ of tubules injured. 

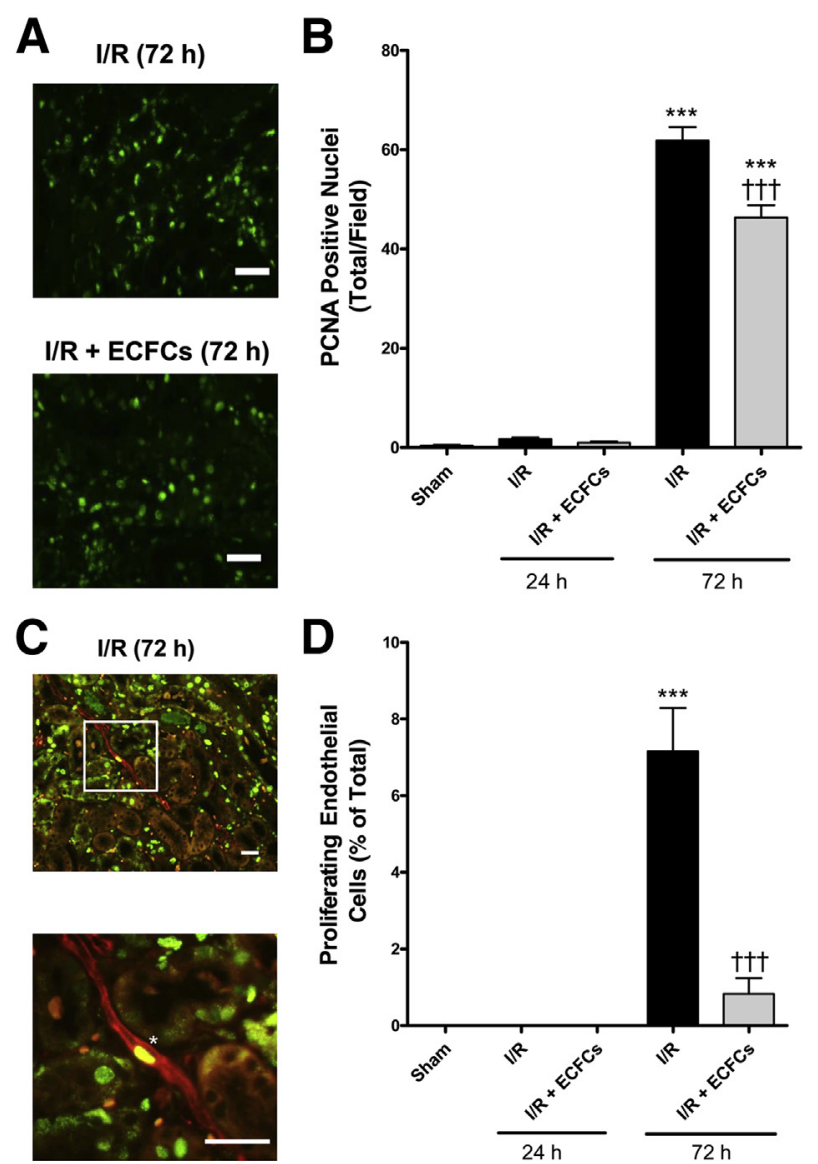

Figure 4 Effect of endothelial colony-forming cells (ECFCS) on tubular and endothelial cell proliferation after ischemia/reperfusion (I/R)-induced acute kidney injury (AKI). Representative images [fluorescein isothiocyanate (FITC) channel; A] and semiquantitative analysis (B) of corticomedullary tubular proliferation, as assessed by proliferating cell nuclear antigen (PCNA; green) immunoreactivity. Objective: Zeiss Plan-Apochromat $20 \times$ (numerical aperture, 0.75; Carl Zeiss AG). ECFCs prevent burst in endothelial PCNA expression in terminal arterioles at 72 hours after I/R. Shown are merged images (rhodamine and FITC channels; C) depicting endothelial cell proliferation in mice subjected to I/R at 72 hours and semiquantitative analysis (D) of endothelial nitric oxide synthase (eNOS; red) - and PCNA (green) - positive cells in kidney sections after I/R. Asterisk shows yellow nucleus indicating dual positive staining for PCNA and eNOS. Low-power image includes inset for high-power image below. Objectives: low power, Zeiss Plan-Apochromat 20× (numerical aperture, 0.75; Carl Zeiss AG); high power, Zeiss Plan-Apochromat $63 \times$ (numerical aperture, 1.4-oil; Carl Zeiss AG). Although no PCNA staining was evident 24 hours after I/R, PCNA staining increased in terminal arterioles at 72 hours. Significantly less PCNA staining was observed in kidneys from mice treated with ECFCs. Data are presented as means \pm SEM (B and $\mathbf{D}) . n=5$ to 6 (B and $\mathbf{D}) .{ }^{* * *} P<0.001$ versus sham; ${ }^{\dagger \dagger} P<0.001$ versus 72 -hour I/R. Scale bar $=20 \mu \mathrm{m}$ (A and $\left.\mathbf{C}\right)$.

Tubular apoptosis was assessed using the terminal deoxynucleotidyl transferase-mediated dUTP nick-end labeling (TUNEL) Apoptosis Detection Kit (Genscript, Piscataway, $\mathrm{NJ}$ ), according to manufacturer's instructions, and expressed as the number of TUNEL-positive nuclei per corticomedullary field, as described. ${ }^{9}$ For brightfield microscopy, slides were mounted using Surgipath Acrytol mounting medium (Leica Microsystem, Richmond, IL). Images were acquired at room temperature on a Zeiss Imager A1 with a Zeiss AxioCam HRc using Axiovision version 1.6 (Carl
Zeiss AG, Oberkochen, Germany). For microscopy requiring oil immersion, Immersol 518 F (Carl Zeiss AG) was used.

\section{Immunohistochemistry}

Expression of megalin, $\alpha$-smooth muscle actin, proliferating cell nuclear antigen, endothelial nitric oxide synthase, and the macrophage-specific glycoprotein F4/80 was evaluated in the corticomedullary regions of kidney sections. After deparaffinization, kidney sections were placed in sodium citrate (pH 6.0) and microwaved for 20 minutes for antigen retrieval. Sections were treated with $0.3 \% \mathrm{H}_{2} \mathrm{O}_{2}-\mathrm{H}_{2} \mathrm{O}$ for 30 minutes, to inhibit endogenous peroxidase activity. Sections were blocked in $10 \%$ goat serum for 30 minutes, and incubated with antibodies to megalin (1:500; Santa Cruz Biotechnology, Inc., Dallas, TX), F4/80 (1:100; eBioscience, San Diego, CA), $\alpha$-smooth muscle actin (1:400; Santa Cruz Biotechnology, Inc.), endothelial nitric oxide synthase (1:100; Fisher Scientific, Waltham, MA), or proliferating cell nuclear antigen (1:100; Santa Cruz Biotechnology, Inc.) overnight at $4^{\circ} \mathrm{C}$. Sections were probed with Alexa 488 (Molecular Probes), Alexa 594 (Molecular Probes), or biotinconjugated antibodies (Vector Laboratories).

Biotinylated samples were incubated with an avidin-biotinperoxidase amplification system (Vector Laboratories) for 30 minutes. Diaminobenzidine (DAB) was used as a chromogen (6 $\mathrm{mg} / \mathrm{mL}, 10$ minutes), and Mayer hematoxylin was used as a counterstain.

For immunofluorescence microscopy, slides were mounted using Vectashield mounting medium (Vector Laboratories). Images were acquired at room temperature on a Zeiss Axioscop2 with a Zeiss AxioCam using Axiovision 3.1 (Carl Zeiss AG). For microscopy requiring oil immersion, Immersol $518 \mathrm{~F}$ (Carl Zeiss AG) was used. For immunofluorescence or DAB staining analysis, images were captured and imported into ImagePro Plus software version 7.0 (Media Cybernetics, Bethesda, MD). Areas of red or green fluorescence or positive DAB staining was measured after background subtraction, and counted as the sum of intensities per field area of view. For intensity of fluorescent and DAB staining, results are expressed as arbitrary units. A minimum of 40 fields of view were assessed.

\section{Measurement of Superoxide Production by Dihydroethidium}

Superoxide production was measured in kidneys by dihydroethidium HPLC, as described with modification. ${ }^{23-25}$ Briefly, whole kidney slices (approximately $5 \mathrm{mg}$ ) were incubated in $400 \mu \mathrm{L}$ of PBS containing $100 \mu \mathrm{mol} / \mathrm{L}$ diethylenetriamine-penta-acetic acid and $50 \mu \mathrm{mol} / \mathrm{L}$ dihydroethidium for 30 minutes at $37^{\circ} \mathrm{C}$ in the dark. Kidneys were then washed in PBS/diethylenetriamine-penta-acetic acid and transferred to liquid nitrogen. Tissues were homogenized with a mortar and pestle, and homogenates were resuspended in $500 \mu \mathrm{L}$ acetonitrile. After sonication, tissue homogenates were centrifuged $\left(12,000 \times g, 10\right.$ minutes, $\left.4^{\circ} \mathrm{C}\right)$, and supernatants were vacuum 


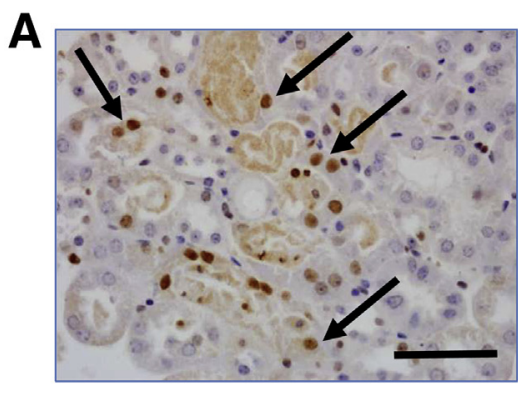

I/R (24 h)

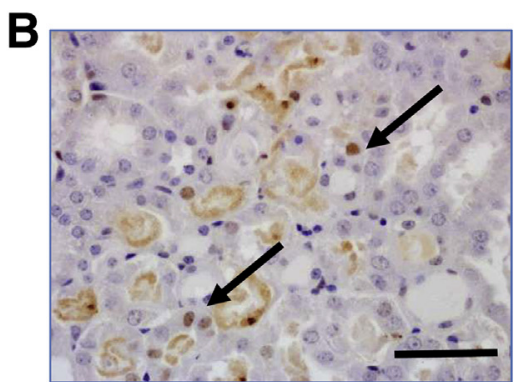

$\mathrm{I} / \mathrm{R}+\mathrm{ECFCs}(24 \mathrm{~h})$

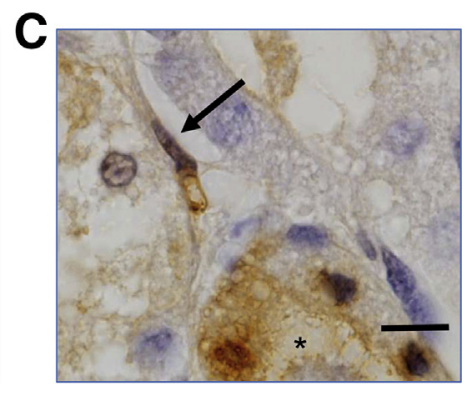

I/R (24 h)
D

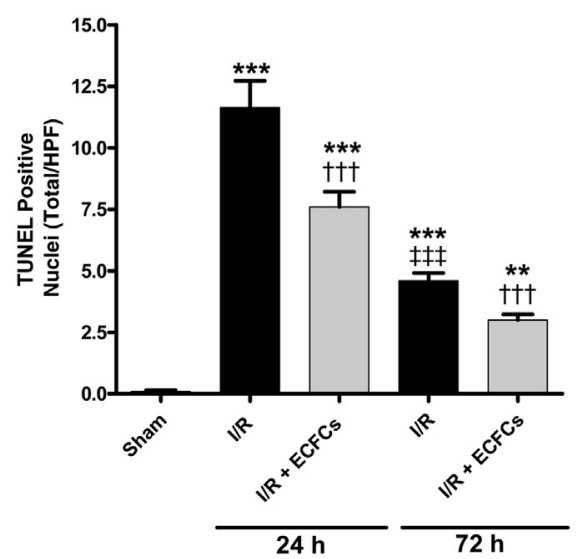

E

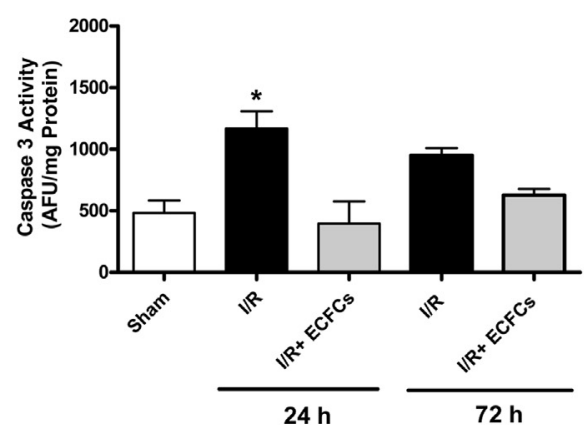

Figure 5 Endothelial colony-forming cells (ECFCs) inhibit apoptosis in ischemia/reperfusion (I/R)-induced acute kidney injury. A-C: Representative images of terminal deoxynucleotidyl transferase-mediated dUTP nick-end labeling (TUNEL) staining. Images from kidney sections from mice subjected to I/R alone (A) or I/R + ECFCs (B) after 24 hours. Arrows indicate TUNEL-positive nuclei. Objective: Zeiss N-Achroplan 40× (numerical aperture, 0.65; Carl Zeiss AG). C: Representative image from mouse kidney (I/R alone, 24 hours) showing an apoptotic endothelial cell (arrow) adjacent to apoptotic tubular cells (asterisk). 0bjective: Zeiss Plan-Apochromat $63 \times$ (numerical aperture, 1.4-oil, Carl Zeiss AG). D: Semiquantitative analysis of TUNEL staining. E: Caspase-3 activity after I/R. Data are presented as means $\pm \mathrm{SEM}$ ( $\mathbf{D}$ and $\mathbf{E}) . n=5$ to 6 (D and $\mathbf{E}) .{ }^{*} P<0.05,{ }^{*} P<0.01$, and ${ }^{* *} P<0.001$ versus sham; ${ }^{\dagger \dagger \dagger} P<0.001$ versus respective I/R control; $\ddagger_{\ddagger \ddagger} P<0.001$ versus 24-hour I/R. Scale bars: $100 \mu \mathrm{m}$ (A and B); $10 \mu \mathrm{m}$ (C). AFU, arbitrary fluorescence units; HPF, high-power field.

dried. The resultant pellets were resuspended in $120 \mu \mathrm{L}$ of $20 \%$ methanol with $0.1 \%$ trifluoroacetic acid, and $100 \mu \mathrm{L}$ was loaded for HPLC analysis. Dihydroethidium and its oxidation products, 2-hydroxyethidium and ethidium, were separated at a flow rate of $0.5 \mathrm{~mL} /$ minute using a $\mathrm{C} 18$ reverse-phase column with a mobile phase containing $0.1 \%$ trifluoroacetic acid and a methanol gradient (from $20 \%$ to $60 \%$ ) over the first 10 minutes. After 10 minutes, the mobile phase was held at $60 \%$ methanol for 10 minutes, followed by a 5-minute wash in $100 \%$ methanol and then a 10-minute re-equilibration in $20 \%$ methanol. Dihydroethidium (the probe, and internal standard) was monitored by UV absorption at $245 \mathrm{~nm}$. Ethidium (representing nonspecific reactive oxygen species) and 2-hydroxyethidium (representing superoxide) were monitored by fluorescence detection, with an excitation of $480 \mathrm{~nm}$ and an emission of $580 \mathrm{~nm}$.

\section{Culture of HUVECS}

HUVECs were obtained from ATCC (Manassas, VA). Cells were cultured at $37^{\circ} \mathrm{C}$ in an atmosphere containing $5 \% \mathrm{CO}_{2}$ in M131 medium supplemented with microvascular growth supplement (Life Technologies, Burlington, ON, Canada). HUVECs at passages 4 to 7 were used for experiments.

\section{H/R Assay}

At the initiation of hypoxia-reoxygenation (H/R), cells were treated with media, ECFC-conditioned media, ECFC-conditioned media without vesicles, ECFC-derived MPs ( $20 \mu \mathrm{g} / \mathrm{mL}$ in media), or ECFC-derived exosomes (20 $\mu \mathrm{g} / \mathrm{mL}$ in media). HUVECs were cultured for 24 hours

Table 1 Distribution of ECFCs after Infusion

\begin{tabular}{llll}
\hline Organ & $\mathrm{T}_{\mathrm{x}}$ & $\mathrm{T}_{1}$ & $\mathrm{~T}_{24}$ \\
\hline Lung & +++ & ++ & + \\
Kidney & + & + & + \\
Heart & + & + & - \\
Brain & - & - & - \\
Spleen & + & + & - \\
Liver & + & - & - \\
Blood $(\%)$ & 15.3 & 1.0 & 0 \\
\hline
\end{tabular}

For blood analysis, the concentration of circulating 5 chloromethylfluorescein diacetate-positive ECFCs was determined by flow cytometry and expressed as a percentage of the concentration of ECFCs initially infused.

ECFC, endothelial colony-forming cells; $T_{x}$, immediately after ECFC infusion; $T_{1}, 1$ hour after infusion; $T_{24}, 24$ hours after infusion; + , rare ( $<1$ cell per field view) $;++$, low density ( 1 to 10 cells per field view) +++ , high density ( $>10$ cells per field view); - , not detected. 

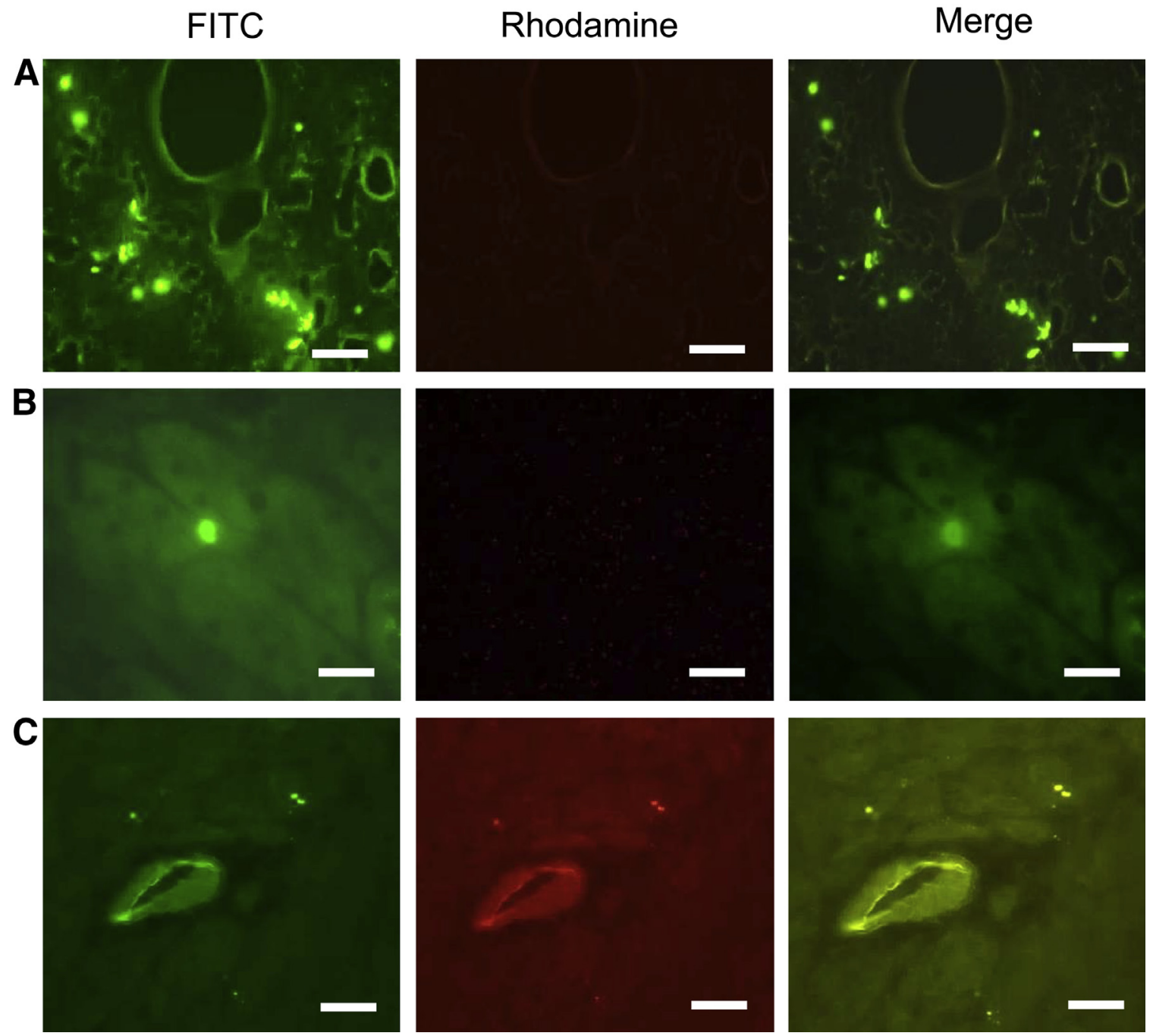

Figure 6 Tissue localization of endothelial colony-forming cells (ECFCs). Fluorescence micrographs [fluorescein isothiocyanate (FITC; left panels); rhodamine (middle panels); merged (right panels)] of 5-chloromethylfluorescein diacetate-labeled ECFCs in mouse lung (A) and kidney (B and C) 1 hour after jugular i.v. infusion of cells at time of reperfusion. Fluorescent ECFCs (green) were observed at low density in the lung (A) and rarely in the kidney (B). C: Rare autofluorescent signals in the kidney were registered and distinguished from ECFCs by non-specific light emission in both FITC and rhodamine channels. Objective: Zeiss Plan-Apochromat 20× (numerical aperture, 0.75; Carl Zeiss AG). Scale bar $=50 \mu \mathrm{m}(\mathbf{A}-\mathbf{C})$.

under hypoxic conditions $\left(94.5 \% \mathrm{~N}_{2}, 5 \% \mathrm{CO}_{2}\right.$, and $0.5 \%$ $\mathrm{O}_{2}$ ) in a sealed humidified chamber at $37^{\circ} \mathrm{C}$. After hypoxia, cells were placed under standard culture conditions for reoxygenation for a further 24 hours.

\section{MP/Exosome Isolation}

MPs and exosomes were isolated from medium collected from cultured ECFCs (passages 3 to 4 ) after 24 hours of culture in medium supplemented with vesicle-depleted fetal bovine serum (System Biosciences, Mountain View, CA), as described with modification. ${ }^{27}$ Briefly, after an initial low-speed centrifugation to discard dead cells and debris $(2500 \times g, 10 \mathrm{mi}-$ nutes), MPs were pelleted after a centrifugation at 20,000 $\times g$ for 20 minutes at $4{ }^{\circ} \mathrm{C}$. The remaining supernatant was used to purify the exosomal fraction after two centrifugations at $100,000 \times g$ for 90 minutes at $4^{\circ} \mathrm{C}$. The final pellets containing the exosome/MP fractions were diluted in radioimmunoprecipitation assay buffer for Western blot analysis or in sterile PBS for cell treatment, nanoparticle tracking analysis, and electron microscopy.

\section{Preparation of Conditioned Medium and Vesicle Fractions for Treatment}

Conditioned medium used to treat HUVECs was collected after 24 hours of incubation with ECFCs in microvesicle-free medium. To obtain MP and exosome fractions, conditioned medium was subjected to differential centrifugation, as above. The resultant exosome and MP fractions were diluted in $1 \times$ PBS, and $20 \mu \mathrm{g} / \mathrm{mL}$ (final concentration) was added to HUVEC cell media. Vesicle concentrations approximate those used in cultured endothelial cells by Wang et al. ${ }^{26}$ Vesicle-free 
A

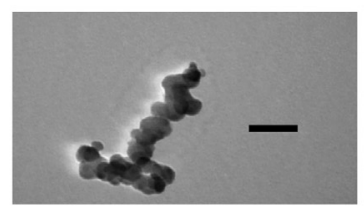

B
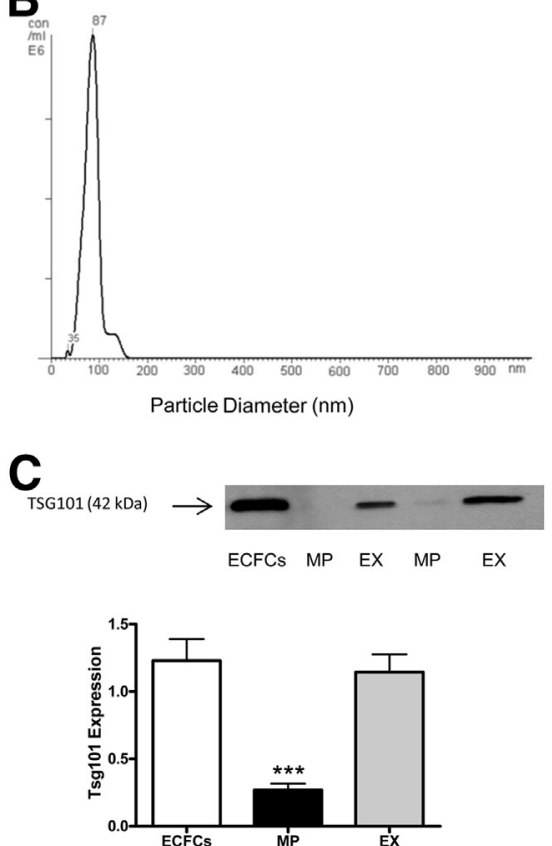
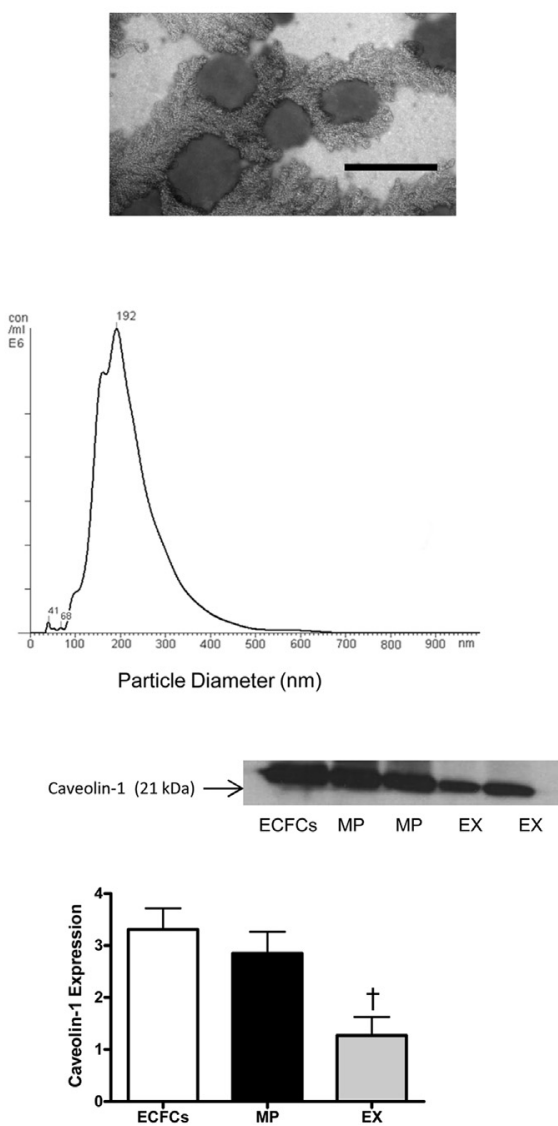

Figure 7 Characterization of endothelial colony-forming cell (ECFC)-derived exosomes (EXs) and microparticles (MPs). Transmission electron micrographs (A) and nanoparticle tracking analysis (B) of EX (left panel) and MP (right panel) fractions from media of cultured ECFCs isolated by differential centrifugation. EX showed a mean size of $86 \mathrm{~nm}$ (mode, $87 \mathrm{~nm}$ ) with $94.0 \%$ within the size range of 40 to $100 \mathrm{~nm}$, MPs had a mean size of $223 \mathrm{~nm}$ (mode, $192 \mathrm{~nm}$ ) with $96.6 \%$ within the size range of 100 to $1000 \mathrm{~nm}$. C: Western blot analysis identifies the exosome marker TSG101 in EX, but not MP, fractions and shows enrichment of caveolin-1 in MPs. Data are presented as means \pm SEM (C). $n=3$ (C). $* * * P<0.001$ versus ECFCs and EX (for TSG101); ${ }^{\dagger} P<0.05$ versus ECFCs and MPs (for caveolin-1). Scale bars: $100 \mathrm{~nm}$ (EX, A, left panel); $500 \mathrm{~nm}$ (MP, A, right panel). conditioned medium was obtained from the supernatant obtained after the final $100,000 \times g$ ultracentrifugation step.

\section{MP/Exosome Characterization by Electron Microscopy}

Isolated exosome or MP fractions were spotted on carboncoated grids (200 mesh; Canemco, Lakefield, ON, Canada). Samples were negatively stained with $1 \%$ uranyl acetate, $\mathrm{pH}$ 7.5, and examined on a Hitachi $\mathrm{H} 7100$ electron microscope (Hitachi High Technologies, Toronto, ON, Canada).

\section{Nanoparticle Tracking Analysis}

Sizing of EVs was performed by nanoparticle tracking analysis with a Nanosight LM10 instrument (NanoSight Limited, Amesbury, UK), as described. ${ }^{28,29}$ A shutter speed of approximately 30 milliseconds was used with a camera gain between 250 and 650. Analysis settings were as follows: detection threshold, 30 to 50 ; blur, $5 \times 5$; minimum expected particle size, auto.

\section{Western Blot Analysis}

Caspase-3 cleavage and intercellular adhesion molecule-1 (ICAM-1) expression was assessed in HUVEC lysates and expressed as the ratio of cleaved caspase-3/total caspase-3 and ICAM-1/glyceraldehyde-3-phosphate dehydrogenase, respectively. Tumor susceptibility gene (TSG)101 (a marker of exosomes) and caveolin-1 (enriched in MPs) were assessed in vesicle fractions as well as ECFC cell lysates $(20 \mu \mathrm{g})$ by Western blot analysis. Membranes were incubated with anti-TSG101 (1:2000; Abcam Inc., Toronto, ON, Canada), anti-caveolin-1 (1:2000; Santa Cruz Biotechnology, Inc.), anti-caspase-3 (1:1000; Cell Signaling, Danvers, MA), anti-cleaved caspase-3 (1:1000; Cell Signaling), and antiICAM-1 (Santa Cruz Biotechnology, Inc.) antibodies overnight at $4^{\circ} \mathrm{C}$. Washed membranes were incubated with the appropriate horseradish peroxidase-conjugated secondary antibodies (1:2000) and probed for immunoreactive proteins by chemiluminescence. Blots were analyzed densitometrically using ImageJ software version 1.48 (NIH, Bethesda, MD; http://imagej.nih.gov/ij).

\section{Caspase-3 Activity}

Caspase-3 activity was measured using the QuantiZyme Assay System (BioMol, Farmingdale, NY), as described. ${ }^{23,30}$ A total of $50 \mu \mathrm{g}$ protein was used for analysis, and results are expressed as arbitrary units/ $\mu \mathrm{g}$ protein.

\section{Statistical Analysis}

Results are expressed as means \pm SEM and were analyzed using a one- or two-way analysis of variance, with a Bonferonni 
post test as appropriate. All statistical analyses were performed with Graphpad Prism version 5.0 (GraphPad Software, Inc., La Jolla, CA). $P<0.05$ was considered significant.

\section{Results}

\section{Effects of ECFCs on I/R-Induced Kidney Injury}

ECFCs were isolated from human umbilical cord blood, grown in culture, and characterized for expression of cell surface antigens. By flow cytometry, ECFCs (passage $4, n=4$ ) expressed high levels of CD31 $(82.5 \% \pm 5.7 \%$ positive) and vascular endothelial growth factor receptor $2(88.5 \% \pm 2.4 \%)$, but lacked significant CD45 $(0.5 \% \pm 0.2 \%), \quad \mathrm{CD} 14$ $(0.9 \% \pm 0.3 \%)$, and $\mathrm{CD} 133(0.8 \% \pm 0.3 \%)$ expression, consistent with our previous report. ${ }^{18}$

The effects of human ECFCs were studied in NOD-SCID mice subjected to 30 minutes of bilateral kidney I/R. Compared with sham-operated on mice, I/R increased plasma creatinine levels at 24 and 72 hours after reperfusion (Figure 1, A and B). Treatment with ECFCs significantly reduced plasma creatinine at both time points. I/R significantly increased BUN levels at 24 hours, and ECFC treatment partially attenuated this increase (Figure 1A). At 72 hours, no significant differences in BUN were seen across all groups (Figure 1B).

Tubular necrosis was assessed by histological scoring of injury. $\mathrm{I} / \mathrm{R}$ caused significant increases in tubular injury scores at 24 and 72 hours after reperfusion (Figure 1, C-E). Treatment with ECFCs significantly reduced tubular injury.

Tubular damage was further assessed by studying expression of megalin, a brush border protein involved in receptormediated endocytosis. ${ }^{31}$ Strong megalin immunoreactivity was observed in proximal tubules from sham-operated on mice. By contrast, megalin staining was significantly reduced in mice subjected to I/R at 24 and 72 hours, an effect significantly attenuated by ECFC treatment (Figure 2, A and B). By immunohistochemistry, kidney $\mathrm{I} / \mathrm{R}$ significantly increased renal cortical levels of the myofibroblast marker $\alpha$-smooth muscle actin at 72 hours after reperfusion, an effect that was inhibited by ECFCs (Figure 2, C and D).

\section{Effects of ECFCs on I/R-Induced Macrophage Infiltration and Oxidative Stress}

Macrophage infiltration and generation of reactive oxygen species are implicated in the pathogenesis of AKI. ${ }^{32,33}$ Kidney I/R markedly increased tissue macrophages at 24 and 72 hours (Figure 3, A-C). Administration of ECFCs had no effect on macrophage infiltration at 24 hours, but significantly reduced levels at 72 hours. I/R also increased renal superoxide formation at 72 hours, an effect that was attenuated by ECFCs (Figure 3D).

\section{Effects of ECFCs on Renal Cell Proliferation after I/R}

Kidney corticomedullary cellular proliferation, assessed by staining for proliferating cell nuclear antigen, was unchanged
A
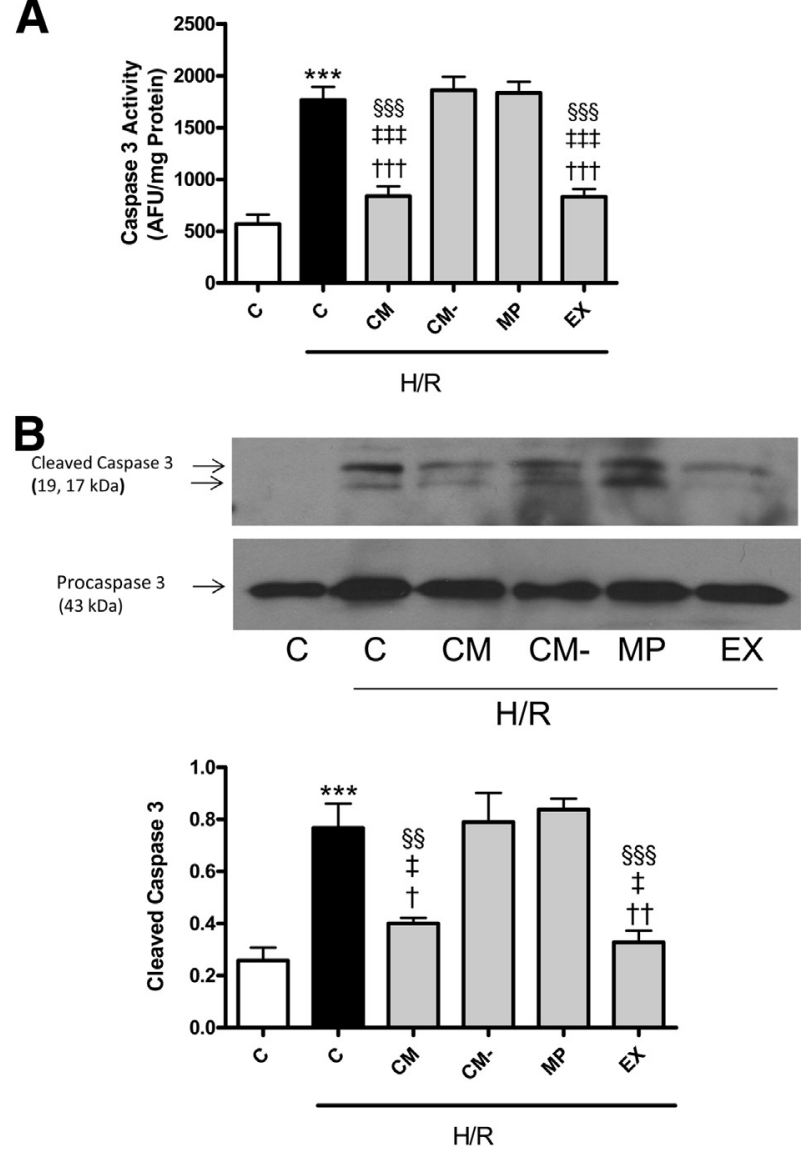

Figure 8 Effect of endothelial colony-forming cell (ECFC)-derived exosomes and microparticles on endothelial caspase-3 activation. Human umbilical vein endothelial cells were incubated under normoxic conditions (C) or in a hypoxic chamber for 24 hours, followed by reoxygenation $(H / R)$, in the absence $(H / R, C)$ or presence of conditioned media from ECFCS (CM), conditioned media without vesicles (CM-), ECFC-derived microparticles (MPs; $20 \mu \mathrm{g} / \mathrm{mL}$ ), or ECFC-derived exosomes (EXs; $20 \mu \mathrm{g} / \mathrm{mL}$ ). A: Caspase-3 activity in treated cells. B: Representative blot and densitometric analysis for cleaved caspase-3 depicted with procaspase immunoblot below. Data are presented as means \pm SEM (A and B). $n=3(\mathbf{A}) ; n=4$ (B). $* * * P<0.001$ versus normoxic conditions $(C) ;{ }^{\dagger} P<0.05,{ }^{\dagger \dagger} P<0.01$, and ${ }^{\dagger \dagger \dagger} P<0.001$ versus H/R C; ${ }^{\ddagger} P<0.05,{ }^{\ddagger \ddagger \ddagger} P<0.001$ versus H/R CM-; ${ }^{\S \S} P<0.01,{ }^{\S \S \S} P<0.001$ versus H/R MP. AFU, arbitrary fluorescence unit.

at 24 hours after I/R, but increased at 72 hours (Figure 4, A and B), and treatment with ECFCs attenuated this increase. Although most proliferating cells were of tubular origin, kidney I/R significantly increased proliferation of endothelial cells at 72 hours, as determined by costaining for endothelial nitric oxide synthase (Figure 4, C and D). Endothelial proliferation was restricted to terminal arterioles and was not detected at 24 hours. Treatment with ECFCs markedly attenuated I/R-induced increases in endothelial proliferation (Figure 4, C and D).

\section{Effect of ECFCs on Apoptosis}

I/R increased renal cell apoptosis, as determined by TUNEL staining and renal caspase-3 activity (Figure 5, A, B, D, and 
E). Treatment with ECFCs blocked I/R-mediated increases in apoptosis. By immunohistochemistry, apoptosis was readily evident in tubular cells at 24 and 72 hours after I/R. Although most apoptotic nuclei were of tubular cell origin $(>95 \%)$, endothelial apoptosis was detectable at 24 hours, but not 72 hours, after I/R (Figure 5C).

\section{In Vivo Distribution of Human ECFCs}

The distribution of CFMDA-labeled ECFCs was examined in blood and tissue sections from mice subjected to bilateral kidney I/R for 30 minutes (Table 1 and Figure 6). ECFCs were detected in blood samples up to 1 hour after injection, but were not observed at 24 hours. Immediately after injection, ECFCs were detected in lung and rarely in kidney, liver, spleen, and heart. At 1 hour, ECFCs were found at low density in lungs, and rarely in other tissues, and by 24 hours, ECFCs were barely detectable in any tissues.

\section{In Vitro Effects of ECFC-Conditioned Media and ECFC-Derived Microvesicles}

Because ECFCs were only rarely observed in kidney sections after injection, we assessed whether ECFCs release EVs that exert protective effects. After 24 hours in culture, ECFCs released exosomes (40- to 100-nm diameter) and MPs (100- to 1000-nm diameter) into the culture medium (Figure 7A). Nanoparticle tracking analysis of exosome and MP fractions demonstrated efficient separation of the two fractions by size, after differential centrifugation (Figure 7B). ECFC-derived exosomes were enriched in exosome markers TSG101 (Figure 7C) and CD63 (data not shown). ${ }^{34}$ MPs were enriched in caveolin-1 (Figure 7C), as described. ${ }^{24}$

To determine the effects of ECFC-derived factors on endothelial injury, we examined the contribution of ECFC-derived exosomes, MPs, and nonvesicular factors in $\mathrm{H} / \mathrm{R}$-induced endothelial cell injury. H/R caused a significant increase in apoptosis, as assessed by caspase-3 cleavage and activity (Figure 8). Treatment with ECFC-conditioned media or exosomes completely blocked the H/R-induced increase in apoptosis. Conversely, treatment with ECFC-derived MPs or ECFC-conditioned medium devoid of vesicles had no effect on H/R-induced endothelial cell apoptosis. Similarly, H/R-induced increases in expression of the proinflammatory protein ICAM$1^{35}$ were blocked by exosomes, whereas MPs were without effect (Figure 9). Notably, under normoxic conditions, MPs stimulated endothelial cell apoptosis (Figure 10A) and expression of ICAM-1 (Figure 10B), whereas exosomes had no effect.

\section{Effects of in Vivo Administration of ECFC-Derived Exosomes on I/R-Induced Renal Injury}

To determine whether ECFC-derived exosomes exert protective effects in vivo, ECFC-derived exosomes were isolated, as above, and administered to NOD-SCID mice subjected to 30 minutes of bilateral kidney I/R. At 24 hours after reperfusion,
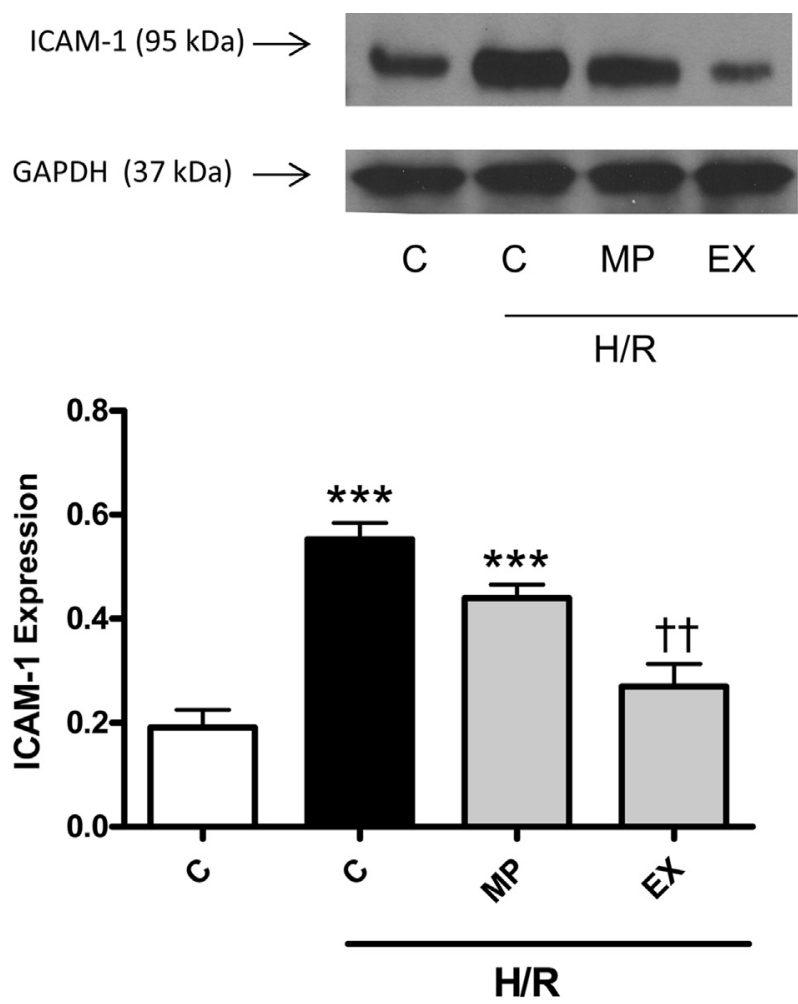

Figure 9 Effect of endothelial colony-forming cell (ECFC)-derived exosomes (EXs) and microparticles (MPs) on endothelial expression of intercellular adhesion molecule 1 (ICAM-1). Human umbilical vein endothelial cells were incubated in a hypoxic chamber for 24 hours $\left(0.5 \% 0_{2}\right)$, followed by reoxygenation $(\mathrm{H} / \mathrm{R})$, in the presence or absence of ECFCderived microparticles (MPs; $20 \mu \mathrm{g} / \mathrm{mL}$ ) or ECFC-derived exosomes (EXs; $20 \mu \mathrm{g} / \mathrm{mL}$ ). ICAM-1 expression was assessed by Western blot analysis and normalized to glyceraldehyde-3-phosphate dehydrogenase (GAPDH) levels. Representative blot is depicted above graph. ${ }^{* *} P<0.001$ versus normoxic control (C); ${ }^{\dagger} P<0.01$ versus H/R C. $n=3$.

exosome administration ( $15 \mu \mathrm{g}$ via jugular vein) was associated with significant attenuation of I/R-induced increases in plasma creatinine (Figure 11A), whereas BUN was not significantly altered (Figure 11B). ECFC-derived exosomes caused significant decreases in tubular necrosis scores (Figure 11, C and D) and apoptosis (Figure 11E).

\section{Discussion}

The present study determined the effects of human cord bloodderived ECFCs in I/R AKI, and the role of vesicle subpopulations. The principal finding is that human ECFCs and their exosomes protect against multiple parameters of renal injury. In vitro experiments showed that ECFC-derived exosomes and ECFC-conditioned media inhibit $\mathrm{H} / \mathrm{R}$-induced caspase-3 activation in cultured endothelial cells. By contrast, neither ECFC-derived MPs nor vesicle-depleted conditioned medium blocked apoptotic responses, and MP administration under normoxic conditions stimulated endothelial apoptotic and inflammatory responses. Taken together, our data suggest that 
ECFCs exert protective effects in ischemic AKI through the release of exosomes and reductions in apoptosis.

\section{Protective Effects of Human ECFCs in Renal I/R Injury}

Although there is extensive preclinical evidence to support the use of cell-based therapy as a strategy for the treatment of AKI, ${ }^{4,5,36}$ the administration of certain progenitor cells of hematopoietic lineage is associated with exacerbation of renal injury in experimental AKI. ${ }^{9,37}$ In the present study, human umbilical cord blood-derived ECFCs lacked hematopoietic markers (ie, CD45 and CD14) and displayed exclusively markers of endothelial lineage. In NOD-SCID mice, we observed that ECFCs attenuated I/R-induced renal injury, as determined by decreases in plasma creatinine. At 24 hours, BUN was significantly increased after I/R, with levels significantly reduced after ECFC administration. In contrast to creatinine, no differences in BUN levels were seen among treatment groups at 72 hours, nor did exosomes significantly reduce BUN at 24 hours. Unlike creatinine, however, BUN is recognized as a suboptimal marker of renal function because levels are affected not only by glomerular filtration but also by production, renal tubular handling, protein intake, and volume status. ${ }^{38}$ Our creatinine data, obtained with a sensitive and specific HPLC assay method ${ }^{20}$ therefore support a beneficial effect of ECFCs and exosomes on renal function. Absence of significant effects on BUN levels could reflect varying volume status in the mice after ischemic renal injury.

The protective effects of ECFC administration were further supported by its association with significant reductions in postischemic tubular necrosis, preservation of brush border, and reductions in renal apoptosis. Moreover, in contrast to human cord blood-derived $\mathrm{CD} 133^{+}$cells, which are proinflammatory, ${ }^{9}$ ECFCs inhibited I/R-induced increases in inflammation (macrophage infiltration) at 72 hours after reperfusion. ECFCs also reduced I/R-induced superoxide production at 72 hours. Because macrophages are enriched in sources of superoxide, such as NADPH oxidase, ${ }^{39,40}$ the reductions in superoxide may be a direct result of decreased macrophage infiltration.

\section{ECFC-Derived Exosomes and MPs as Mediators of Paracrine Signals in I/R Injury}

Evidence strongly suggests that the beneficial effects of cell therapy in ischemic injury are achieved through the release of secreted factors. ${ }^{13,41,42}$ Consistently, we observed only rare incorporation of ECFCs into kidneys. The lung may be a major homing site because it is the first capillary vascular bed encountered by the ECFCs, which are infused into the mouse jugular vein. Indeed, our data suggest that some trapping of ECFCs in the lung vasculature occurs early after infusion, although the effects of ECFCs do not require significant homing to the site of injury or long-term persistence of cells. Accordingly, cells
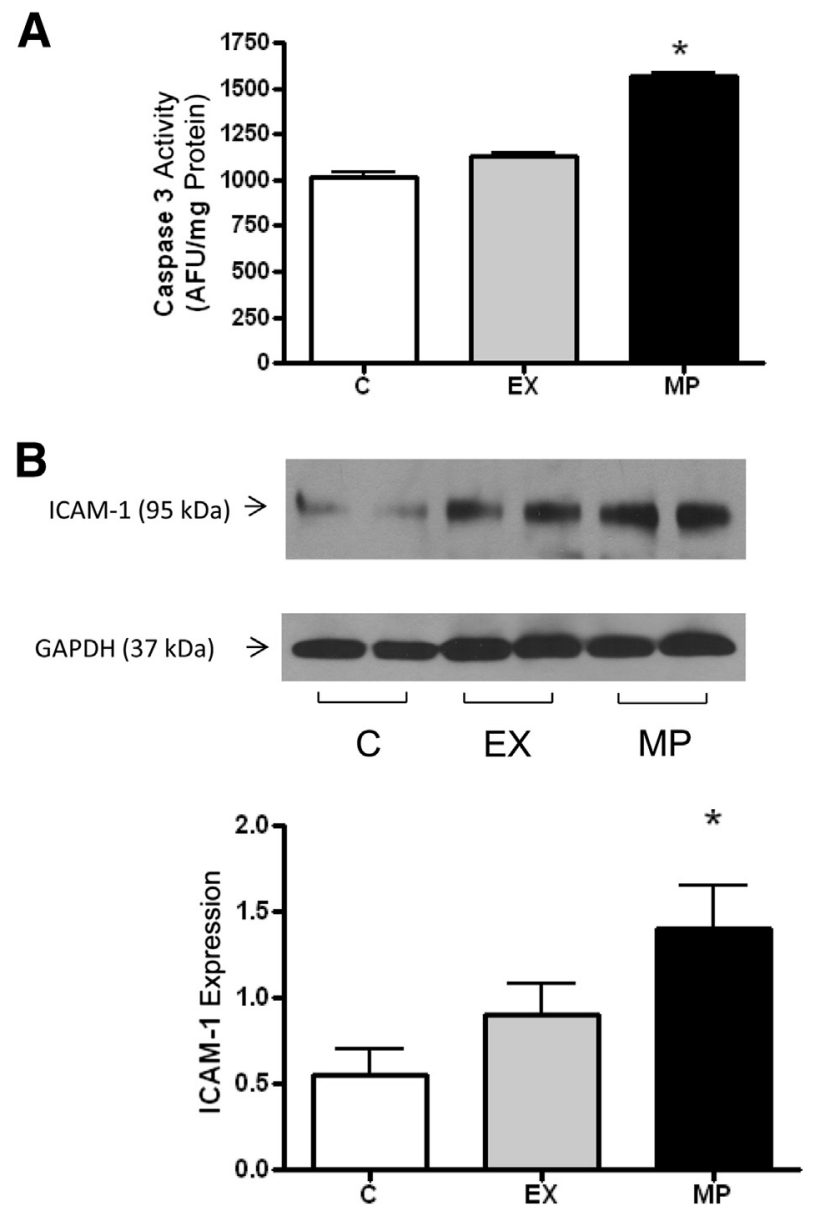

Figure 10 Effect of endothelial colony-forming cell (ECFC)-derived exosomes (EXs) and microparticles (MPs) on apoptosis (A) and expression of intercellular adhesion molecule-1 (ICAM-1; B) in normoxic endothelial cells. Human umbilical vein endothelial cells were incubated in the presence or absence of ECFC-derived microparticles (MPs; $20 \mu \mathrm{g} / \mathrm{mL}$ ) or ECFC-derived exosomes (EXs; $20 \mu \mathrm{g} / \mathrm{mL}$ ). A: Caspase-3 activity expressed as arbitrary fluorescence units (AFUs)/mg protein. B: ICAM-1 expression was assessed by Western blot analysis and normalized to glyceraldehyde-3-phosphate dehydrogenase (GAPDH) levels. Representative blot is depicted. ${ }^{*} P<0.05$ versus control (C). $n=3(\mathbf{A}$ and $\mathbf{B})$.

may act systemically through the release of secreted factors, which then act at the site of injury. One putative mechanism of action is the release of membrane vesicles into the extracellular space. EVs are broadly divided into three classes: exosomes, MPs, and apoptotic bodies. ${ }^{43}$ Exosomes are small (40- to $100-\mathrm{nm}$ ) vesicles secreted by exocytosis when multivesicular bodies fuse with the plasma membrane. MPs are larger membrane fragments $(0.1$ to $1 \mu \mathrm{m})$ released from cells through outward membrane blebbing under conditions of stress/injury. Apoptotic bodies are the largest of the three classes ( 1 to $5 \mu \mathrm{m})$ and are formed exclusively during the late phases of apoptosis. Considerable differences in the biological actions of EVs may exist, depending on origin. ${ }^{43}$ Cantaluppi and colleagues ${ }^{14,17}$ have reported that a mixed vesicle population (mean size, $159 \mathrm{~nm}$ ), derived from human endothelial 


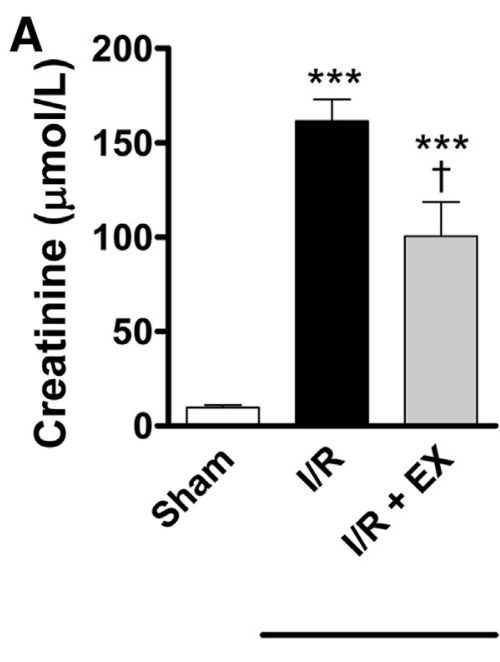

$24 \mathrm{~h}$

C

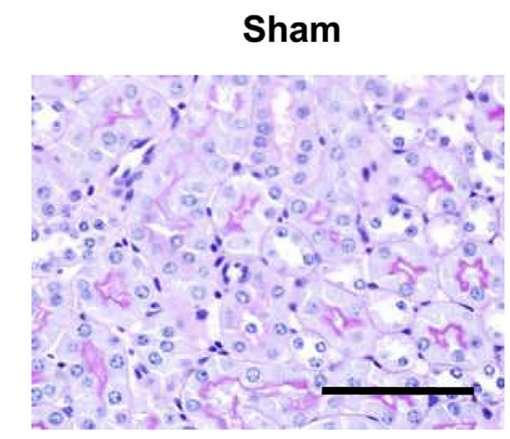

D

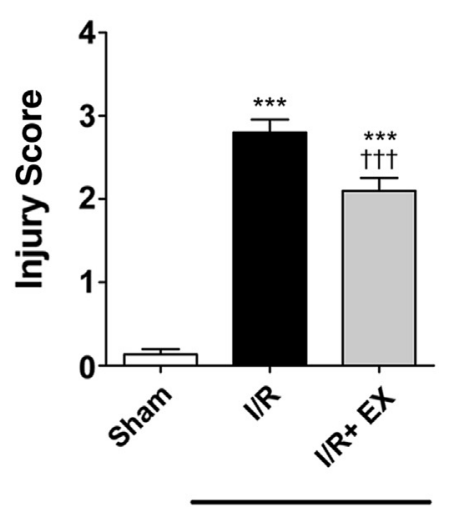

$24 \mathrm{~h}$
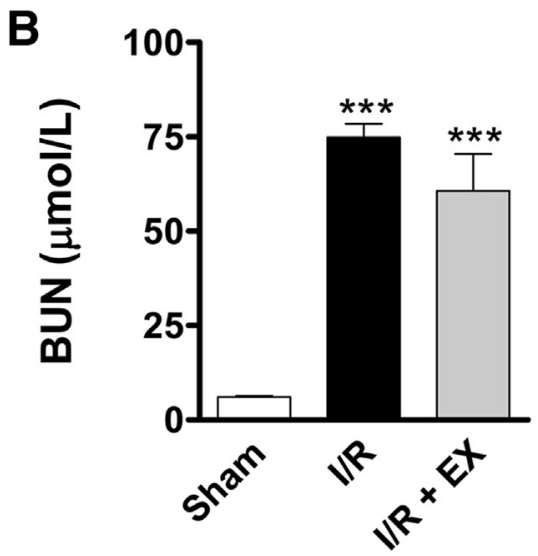

$24 \mathrm{~h}$
I/R (24 h)

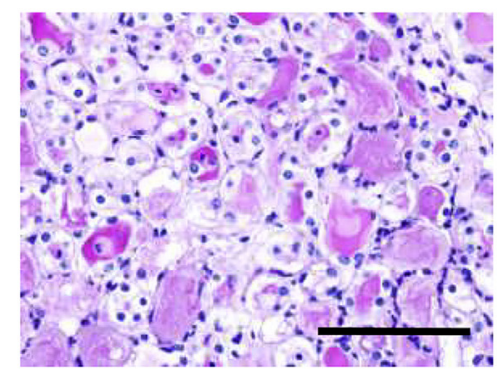

E

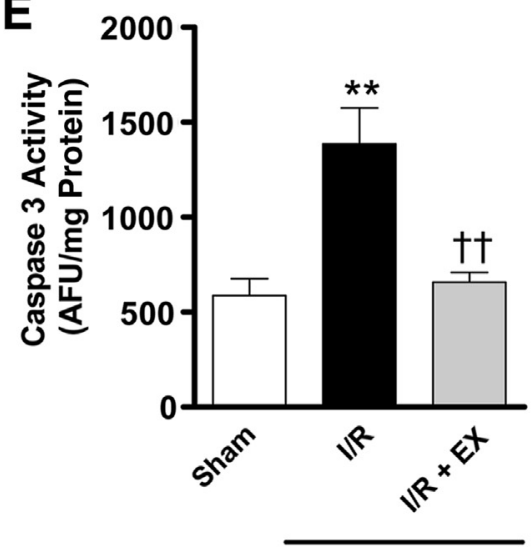

$24 \mathrm{~h}$
Figure 11 Effect of endothelial colonyforming cell (ECFC)-derived exosomes (EXs) on kidney ischemia/reperfusion (I/R) injury in mice. Mice were subjected to sham surgery or 30 minutes of kidney ischemia, followed by 24 hours of reperfusion, and treated with ECFC-derived EXs ( $15 \mu \mathrm{g}$ per mouse, i.v., via jugular vein) or vehicle at the time of reperfusion. Plasma creatinine (A) and blood urea nitrogen (BUN; B) levels in mice at 24 hours' reperfusion. Representative images (C) and scoring (D) of corticomedullary tubular injury. Objective: Zeiss Plan-Apochromat 20× (numerical aperture, 0.80; Carl Zeiss AG). E: Apoptosis as assessed by caspase-3 activity and TUNEL staining. ${ }^{* *} P<0.01$ $* * * P<0.001$ versus sham; ${ }^{\dagger} P<0.05$, ${ }^{\dagger \dagger} P<0.01$, and ${ }^{\dagger \dagger \dagger} P<0.001$ versus $\mathrm{I} / \mathrm{R}$ control. $n=6$ to 7 mice per group (A, B, D, and $\mathbf{E})$. Scale bar $=100 \mu \mathrm{m}$. AFU, arbitrary fluorescence unit.

\section{I/R + EX (24 h)}
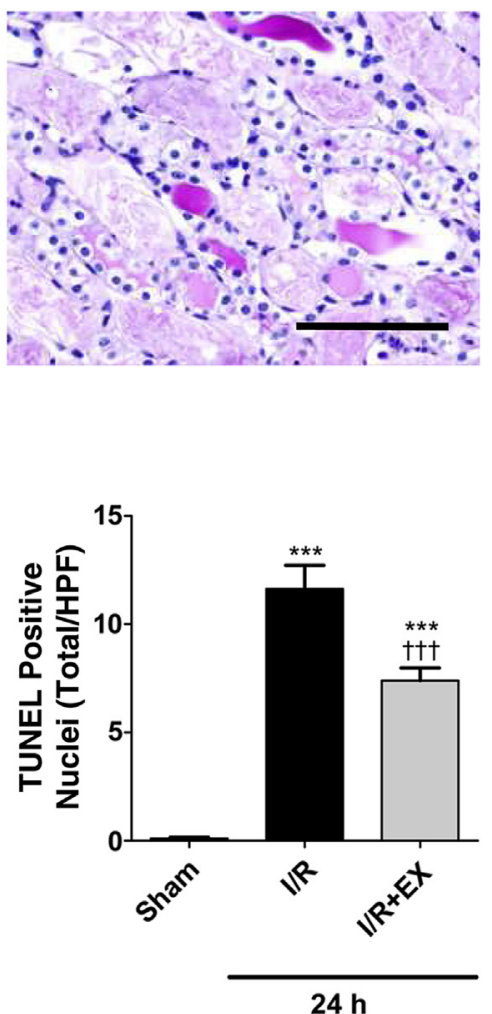

progenitor cells, is protective when administered to mice with AKI. Similarly, mesenchymal stem cell-derived exosomes protect against cisplatin-induced AKI in mice, when injected directly into kidneys. ${ }^{44}$ Vesicle-independent effects have also been reported as adipose-derived mesenchymal stem cells release growth factors that are protective in nephrotoxic AKI models. ${ }^{45,46}$

In the present study, potential mediators of endothelial cell protection by ECFCs were examined by separation of secreted factors into exosome, MP, and nonvesicular fractions. ECFCderived exosomes completely inhibited H/R-induced apoptotic and proinflammatory responses, whereas MPs and conditioned media lacking vesicles were without effect. Indeed, under normoxic conditions, MPs actually promoted both caspase activation and ICAM-1 expression. More important, administration of ECFC-derived exosomes in vivo was associated with a reduction in renal injury. In view of these data, the separation of exosomes from MPs in ECFC-derived EV 
preparations may enhance therapeutic efficacy compared with mixed populations.

\section{Endothelial Response to ECFC Administration in Renal I/R}

Renal recovery after AKI involves both tubular and endothelial regeneration, with the latter being of particular importance in the extension phase, where continued hypoxia and inflammatory responses lead to prolonged renal dysfunction. $^{47}$ Although endothelial cell apoptosis was identified after I/R in vivo, the levels were relatively low and difficult to quantify. Indeed, endothelial apoptosis in AKI is extremely difficult to detect, at least partly because of the tendency of apoptotic endothelial cells to detach (anoikis). ${ }^{4,47}$ In the present studies, ECFCs also influenced postischemic endothelial proliferation. At 72 hours after I/R, both tubular and endothelial cell proliferation were significantly enhanced, and markedly decreased by ECFC administration. In this regard, renal recovery is most commonly associated with enhanced endothelial and tubular proliferation, ${ }^{14,44,48}$ and a decrease in proliferation may therefore represent a maladaptive response. Conversely, Yang et $\mathrm{al}^{21}$ have reported decreased cell proliferation despite renal protection associated with erythropoietin administration. One possible explanation is that erythropoietin and ECFCs attenuate postischemic renal injury, thereby reducing the need for reparative cell proliferation. By preserving endothelial cell function after I/R, ECFCs could indirectly diminish indexes of tubular cell injury (necrosis, megalin loss, and apoptosis), as we observed in vivo. Although the renal endothelium represents the likely first point of contact for infused ECFCs, it is possible that their exosomes and other EVs might access the tubulointerstitium and modulate epithelial cell function, as has been suggested. $^{14}$

\section{Therapeutic Considerations}

A key observation from the present study is that ECFCderived exosomes are primary mediators of the antiapoptotic effects of ECFCs, independent of other vesicle populations. This suggests that administration of exosomes alone may provide protection against ischemic AKI. The precise mechanisms by which exosomes achieve these effects are unclear, although horizontal transfer of miRNA has been implicated in the beneficial effects of other vesicle populations. ${ }^{14}$ Regardless of mechanism, the therapeutic delivery of exosomes in AKI may offer several advantages over nonselective vesicle isolation or whole cell delivery. First, the presence of MP in vesicle preparations may dilute or even counteract the effects of exosomes through the induction of proinflammatory pathways. Second, exosomes also have been shown to exhibit decreased immunogenicity, ${ }^{49,50}$ although this was not examined in the present study, which was conducted in immune-compromised mice.
Moreover, although exogenous cells may become trapped in the lung microvasculature after infusion, ${ }^{51}$ exosomes may be more likely to reach the wanted therapeutic target, because of their small size. ${ }^{52}$ Finally, cell therapy carries the risk of donor-derived tumor development, ${ }^{53}$ a complication not expected with delivery of exosomes, which lack machinery for replication.

In summary, our data indicate that human ECFCs and their exosomes protect against ischemic AKI in mice. In vitro studies reveal that exosomes, but not MPs or other secreted factors, are the primary mediators of ECFCmediated endothelial protection from apoptosis. These results suggest that the use of human ECFCs or ECFCderived exosomes may represent a viable strategy to protect against ischemic endothelial injury in AKI.

\section{Acknowledgments}

We thank Dr. Charlie Thompson (University of Ottawa) for assistance with the hypoxia and reoxygenation studies.

\section{References}

1. James M, Bouchard J, Ho J, Klarenbach S, LaFrance JP, Rigatto C, Wald R, Zappitelli M, Pannu N: Canadian Society of Nephrology commentary on the 2012 KDIGO clinical practice guideline for acute kidney injury. Am J Kidney Dis 2013, 61:673-685

2. Bonventre JV, Yang L: Cellular pathophysiology of ischemic acute kidney injury. J Clin Invest 2011, 121:4210-4221

3. Basile DP: The endothelial cell in ischemic acute kidney injury: implications for acute and chronic function. Kidney Int 2007, 72 151-156

4. Liang CJ, Shen WC, Chang FB, Wu VC, Wang SH, Young GH, Tsai JS, Tseng YC, Peng YS, Chen YL: Endothelial progenitor cells derived from Wharton's jelly of human umbilical cord attenuate ischemic acute kidney injury by increasing vascularization and decreasing apoptosis, inflammation, and fibrosis. Cell Transplant 2014, [Epub ahead of print], http://dx.doi.org/10.3727/ 096368914 X681720

5. Morigi M, Benigni A: Mesenchymal stem cells and kidney repair. Nephrol Dial Transplant 2013, 28:788-793

6. Patschan D, Patschan S, Muller GA: Endothelial progenitor cells in acute ischemic kidney injury: strategies for increasing the cells renoprotective competence. Int J Nephrol 2011, 2011:828369

7. Togel FE, Westenfelder C: Kidney protection and regeneration following acute injury: progress through stem cell therapy. Am J Kidney Dis 2012, 60:1012-1022

8. Suuronen EJ, Wong S, Kapila V, Waghray G, Whitman SC, Mesana TG, Ruel M: Generation of CD133+ cells from CD133peripheral blood mononuclear cells and their properties. Cardiovasc Res 2006, 70:126-135

9. Burger D, Gutsol A, Carter A, Allan DS, Touyz RM, Burns KD Human cord blood CD133+ cells exacerbate ischemic acute kidney injury in mice. Nephrol Dial Transplant 2012, 27:3781-3789

10. Brodsky SV, Yamamoto T, Tada T, Kim B, Chen J, Kajiya F, Goligorsky MS: Endothelial dysfunction in ischemic acute renal failure: rescue by transplanted endothelial cells. Am J Physiol Renal Physiol 2002, 282:F1140-F1149

11. Yoder MC, Mead LE, Prater D, Krier TR, Mroueh KN, Li F, Krasich R, Temm CJ, Prchal JT, Ingram DA: Redefining endothelial 
progenitor cells via clonal analysis and hematopoietic stem/progenitor cell principals. Blood 2007, 109:1801-1809

12. Oh BJ, Kim DK, Kim BJ, Yoon K-S, Park SG, Park KS, Lee M-S, Kim K-W, Kim JH: Differences in donor CXCR4 expression levels are correlated with functional capacity and therapeutic outcome of angiogenic treatment with endothelial colony forming cells. Biochem Biophys Res Commun 2010, 398:627-633

13. Baraniak PR, McDevitt TC: Stem cell paracrine actions and tissue regeneration. Regen Med 2010, 5:121-143

14. Cantaluppi V, Gatti S, Medica D, Figliolini F, Bruno S, Deregibus MC, Sordi A, Biancone L, Tetta C, Camussi G: Microvesicles derived from endothelial progenitor cells protect the kidney from ischemia-reperfusion injury by microRNA-dependent reprogramming of resident renal cells. Kidney Int 2012, 82:412-427

15. Bruno S, Grange C, Collino F, Deregibus MC, Cantaluppi V, Biancone L, Tetta C, Camussi G: Microvesicles derived from mesenchymal stem cells enhance survival in a lethal model of acute kidney injury. PLoS One 2012, 7:e33115

16. Bruno S, Grange C, Deregibus MC, Calogero RA, Saviozzi S, Collino F, Morando L, Busca A, Falda M, Bussolati B, Tetta C, Camussi G: Mesenchymal stem cell-derived microvesicles protect against acute tubular injury. J Am Soc Nephrol 2009, 20:1053-1067

17. Sanchez MB, Bruno S, Grange C, Tapparo M, Cantaluppi V, Tetta C, Camussi G: Human liver stem cells and derived extracellular vesicles improve recovery in a murine model of acute kidney injury. Stem Cell Res Ther 2014, 5:124

18. Sun J, Li Y, Graziani GM, Filion L, Allan DS: E-selectin mediated adhesion and migration of endothelial colony forming cells is enhanced by SDF-1alpha/CXCR4. PLoS One 2013, 8:e60890

19. Pawley J: Handbook of Biological Confocal Microscopy. $3^{\text {rd }}$ Edition. New York, NY, Springer, 2006, pp 985

20. Dunn SR, Qi Z, Bottinger EP, Breyer MD, Sharma K: Utility of endogenous creatinine clearance as a measure of renal function in mice. Kidney Int 2004, 65:1959-1967

21. Yang CW, Li C, Jung JY, Shin SJ, Choi BS, Lim SW, Sun BK, Kim YS, Kim J, Chang YS, Bang BK: Preconditioning with erythropoietin protects against subsequent ischemia-reperfusion injury in rat kidney. FASEB J 2003, 17:1754-1755

22. Yoshida T, Sugiura H, Mitobe M, Tsuchiya K, Shirota S, Nishimura S, Shiohira S, Ito H, Nobori K, Gullans SR, Akiba T, Nitta K: ATF3 protects against renal ischemia-reperfusion injury. J Am Soc Nephrol 2008, 19:217-224

23. Burger D, Kwart DG, Montezano AC, Read NC, Kennedy CR, Thompson CS, Touyz RM: Microparticles induce cell cycle arrest through redox-sensitive processes in endothelial cells: implications in vascular senescence. J Am Heart Assoc 2012, 1:e001842

24. Burger D, Montezano AC, Nishigaki N, He Y, Carter A, Touyz RM: Endothelial microparticle formation by angiotensin II is mediated via Ang II receptor type I/NADPH oxidase/Rho kinase pathways targeted to lipid rafts. Arterioscler Thromb Vasc Biol 2011, 31:1898-1907

25. Fernandes DC, Wosniak J Jr, Pescatore LA, Bertoline MA, Liberman M, Laurindo FR, Santos CX: Analysis of DHE-derived oxidation products by HPLC in the assessment of superoxide production and NADPH oxidase activity in vascular systems. Am J Physiol Cell Physiol 2007, 292:C413-C422

26. Wang J, Chen S, Ma X, Cheng C, Xiao X, Chen J, Liu S, Zhao B, Chen Y: Effects of endothelial progenitor cell-derived microvesicles on hypoxia/reoxygenation-induced endothelial dysfunction and apoptosis. Oxid Med Cell Longev 2013, 2013:572729

27. Ostrowski M, Carmo NB, Krumeich S, Fanget I, Raposo G, Savina A, Moita CF, Schauer K, Hume AN, Freitas RP, Goud B, Benaroch P, Hacohen N, Fukuda M, Desnos C, Seabra MC, Darchen F, Amigorena S, Moita LF, Thery C: Rab27a and Rab27b control different steps of the exosome secretion pathway. Nat Cell Biol 2010, 12:19-30. supp 11-13

28. Burger D, Thibodeau JF, Holterman CE, Burns KD, Touyz RM, Kennedy CR: Urinary podocyte microparticles identify pre-albuminuric diabetic glomerular injury. J Am Soc Nephrol 2014 25:1401-1407

29. Gardiner C, Ferreira YJ, Dragovic RA, Redman CW, Sargent IL: Extracellular vesicle sizing and enumeration by nanoparticle tracking analysis. J Extracell Vesicles 2013, 2:19671

30. Burger D, Lei M, Geoghegan-Morphet N, Lu X, Xenocostas A, Feng Q: Erythropoietin protects cardiomyocytes from apoptosis via up-regulation of endothelial nitric oxide synthase. Cardiovasc Res 2006, 72:51-59

31. Christensen EI, Birn H, Storm T, Weyer K, Nielsen R: Endocytic receptors in the renal proximal tubule. Physiology (Bethesda) 2012, 27:223-236

32. Jo SK, Sung SA, Cho WY, Go KJ, Kim HK: Macrophages contribute to the initiation of ischaemic acute renal failure in rats. Nephrol Dial Transplant 2006, 21:1231-1239

33. Oh DJ, Dursun B, He Z, Lu L, Hoke TS, Ljubanovic D, Faubel S, Edelstein CL: Fractalkine receptor (CX3CR1) inhibition is protective against ischemic acute renal failure in mice. Am J Physiol Renal Physiol 2008, 294:F264-F271

34. Thery C, Ostrowski M, Segura E: Membrane vesicles as conveyors of immune responses. Nat Rev Immunol 2009, 9:581-593

35. Sugimoto H, Shikata K, Hirata K, Akiyama K, Matsuda M, Kushiro M, Shikata Y, Miyatake N, Miyasaka M, Makino H: Increased expression of intercellular adhesion molecule-1 (ICAM-1) in diabetic rat glomeruli: glomerular hyperfiltration is a potential mechanism of ICAM-1 upregulation. Diabetes 1997, 46:2075-2081

36. Patschan D, Patschan S, Wessels JT, Becker JU, David S, Henze E, Goligorsky MS, Muller GA: Epac-1 activator 8-O-cAMP augments renoprotective effects of syngeneic [corrected] murine EPCs in acute ischemic kidney injury. Am J Physiol Renal Physiol 2010, 298: F78-F85

37. Patschan D, Backhaus R, Elle HJ, Schwarze K, Henze E, Becker JU, Patschan S, Muller GA: Angiopoietin-2 modulates eEOC-mediated renoprotection in AKI in a dose-dependent manner. J Nephrol 2013, 26:667-674

38. Waikar SS, Bonventre JV: Can we rely on blood urea nitrogen as a biomarker to determine when to initiate dialysis? Clin J Am Soc Nephrol 2006, 1:903-904

39. Tojo A, Asaba K, Onozato ML: Suppressing renal NADPH oxidase to treat diabetic nephropathy. Expert Opin Ther Targets 2007, 11: $1011-1018$

40. Touyz RM, Briones AM, Sedeek M, Burger D, Montezano AC: NOX isoforms and reactive oxygen species in vascular health. Mol Interv 2011, 11:27-35

41. Ratajczak MZ, Kucia M, Jadczyk T, Greco NJ, Wojakowski W, Tendera M, Ratajczak J: Pivotal role of paracrine effects in stem cell therapies in regenerative medicine: can we translate stem cell-secreted paracrine factors and microvesicles into better therapeutic strategies? Leukemia 2012, 26:1166-1173

42. Imai N, Kaur T, Rosenberg ME, Gupta S: Innovation in the treatment of uremia: proceedings from the Cleveland Clinic Workshop: cellular therapy of kidney diseases. Semin Dial 2009, 22:629-635

43. Burger D, Schock S, Thompson CS, Montezano AC, Hakim AM, Touyz RM: Microparticles: biomarkers and beyond. Clin Sci (Lond) 2013, 124:423-441

44. Zhou Y, Xu H, Xu W, Wang B, Wu H, Tao Y, Zhang B, Wang M, Mao F, Yan Y, Gao S, Gu H, Zhu W, Qian H: Exosomes released by human umbilical cord mesenchymal stem cells protect against cisplatin-induced renal oxidative stress and apoptosis in vivo and in vitro. Stem Cell Res Ther 2013, 4:34

45. Katsuno T, Ozaki T, Saka Y, Furuhashi K, Kim H, Yasuda K, Yamamoto T, Sato W, Tsuboi N, Mizuno M, Ito Y, Imai E, Matsuo S, Maruyama S: Low serum cultured adipose tissue-derived stromal cells ameliorate acute kidney injury in rats. Cell Transplant 2013, 22: 287-297

46. Yasuda K, Ozaki T, Saka Y, Yamamoto T, Gotoh M, Ito Y, Yuzawa Y, Matsuo S, Maruyama S: Autologous cell therapy for 
cisplatin-induced acute kidney injury by using non-expanded adipose tissue-derived cells. Cytotherapy 2012, 14:1089-1100

47. Basile DP, Anderson MD, Sutton TA: Pathophysiology of acute kidney injury. Compr Physiol 2012, 2:1303-1353

48. Li B, Cohen A, Hudson TE, Motlagh D, Amrani DL, Duffield JS: Mobilized human hematopoietic stem/progenitor cells promote kidney repair after ischemia/reperfusion injury. Circulation 2010, 121: $2211-2220$

49. Frangsmyr L, Baranov V, Nagaeva O, Stendahl U, Kjellberg L, Mincheva-Nilsson L: Cytoplasmic microvesicular form of Fas ligand in human early placenta: switching the tissue immune privilege hypothesis from cellular to vesicular level. Mol Hum Reprod 2005, 11:35-41

50. Ichim TE, Zhong Z, Kaushal S, Zheng X, Ren X, Hao X, Joyce JA, Hanley HH, Riordan NH, Koropatnick J, Bogin V, Minev BR,
Min WP, Tullis RH: Exosomes as a tumor immune escape mechanism: possible therapeutic implications. J Transl Med 2008, 6:37

51. Schrepfer S, Deuse T, Reichenspurner H, Fischbein MP, Robbins RC, Pelletier MP: Stem cell transplantation: the lung barrier. Transplant Proc 2007, 39:573-576

52. Takahashi $Y$, Nishikawa $M$, Shinotsuka H, Matsui $Y$, Ohara $S$, Imai T, Takakura Y: Visualization and in vivo tracking of the exosomes of murine melanoma B16-BL6 cells in mice after intravenous injection. J Biotechnol 2013, 165:77-84

53. Amariglio N, Hirshberg A, Scheithauer BW, Cohen Y, Loewenthal R, Trakhtenbrot L, Paz N, Koren-Michowitz M, Waldman D, Leider-Trejo L, Toren A, Constantini S, Rechavi G: Donor-derived brain tumor following neural stem cell transplantation in an ataxia telangiectasia patient. PLoS Med 2009, 6: e1000029 